\title{
An Examination of Family Communication within the Core and Balance Model of Family Leisure Functioning
}

Kevin M. Smith

Brigham Young University - Provo

Follow this and additional works at: https://scholarsarchive.byu.edu/etd

Part of the Recreation Business Commons

\section{BYU ScholarsArchive Citation}

Smith, Kevin M., "An Examination of Family Communication within the Core and Balance Model of Family Leisure Functioning" (2005). Theses and Dissertations. 621.

https://scholarsarchive.byu.edu/etd/621

This Thesis is brought to you for free and open access by BYU ScholarsArchive. It has been accepted for inclusion in Theses and Dissertations by an authorized administrator of BYU ScholarsArchive. For more information, please contact scholarsarchive@byu.edu, ellen_amatangelo@byu.edu. 


\title{
AN EXAMINATION OF FAMILY COMMUNICATION WITHIN \\ THE CORE AND BALANCE MODEL OF FAMILY LEISURE FUNCTIONING \\ by
}

Kevin Michael Smith

\begin{abstract}
A thesis submitted to the faculty of
Brigham Young University

in partial fulfillment of the requirements for the degree of

Master of Science
\end{abstract}

Department of Recreation Management and Youth Leadership

Brigham Young University

August 2005 
Copyright (C) 2005 Kevin Smith

All Rights Reserved 


\title{
BRIGHAM YOUNG UNIVERSITY
}

\section{GRADUATE COMMITTEE APPROVAL}

\author{
of a thesis submitted by
}

Kevin M. Smith

This thesis has been read by each member of the following graduate committee and by majority vote has been found to be satisfactory.

Date

Date

Date
Patti A. Freeman, Chair

Ramon B. Zabriskie
Guy Dorius 


\section{BRIGHAM YOUNG UNIVERSITY}

As chair of the candidate's graduate committee, I have read the thesis of Kevin Smith in its final form and have found that (1) its format, citations, and bibliographical style are consistent and acceptable and fulfill university and department style requirements; (2) its illustrative materials including figures, tables, and charts are in place; and (3) the final manuscript is satisfactory to the graduate committee and is ready for submission to the university library.

Date

Accepted for the Department
Patti A. Freeman

Chair, Graduate Committee
Brian J. Hill

Chair, Department of Recreation Management and Youth Leadership

Accepted for the College

Gordon B. Lindsay, Associate Dean

College of Health and Human Performance 


\begin{abstract}
AN EXAMINATION OF FAMILY COMMUNICATION WITHIN

THE CORE AND BALANCE MODEL OF FAMILY LEISURE

FUNCTIONING

Kevin Michael Smith

Department of Recreation Management and Youth Leadership

Master of Science
\end{abstract}

The purpose of this study was to examine family communication within the Core and Balance Model of Family Leisure Functioning. This was accomplished using path analysis, specifically using a mediator model. Family leisure was measured using the Family Leisure Activity Profile (FLAP), family functioning using the Family Adaptability and Cohesion Evaluation Scales (FACES II), and family communication using the Family Communication Scale (FCS). The sample was youth $(\mathrm{n}=90)$ and parents $(n=123)$ from 25 different states in the US. Family leisure involvement predicted family functioning variables from the youth and family perspectives, but only partially from the parent perspective. Family leisure also predicted family communication from the youth and family perspectives, but not from the parent perspective. Family communication predicted family functioning from all of the perspectives. Path analyses from the youth perspective indicated that the relationship between core family leisure and 
family flexibility was mediated by family communication, as well as the relationship between balance family leisure and family cohesion. Path analyses from the parent perspective indicated the same mediation by communication as the youth, with an addition of the mediation of the relationship between balance family leisure and family flexibility. The data indicated that family communication does mediate some of the relationship between family leisure involvement and family functioning. 


\section{ACKNOWLEDGMENTS}

I would like to thank my thesis chair, Patti, for all the help and long arduous hours she spent helping me complete this thesis. I also wish to thank Ramon and Guy for their input and support. I must thank Birgitta for the help in coming up with the proper analysis to test my idea, and for helping me run the analysis correctly. I also need to thank Sandy for her formatting help. And I can’t leave out Toni, whose thesis I used a lot in seeing how it was done and the members of my band, Early California, for letting me slack off while finishing my thesis. And, of course, I must thank my mom and dad for their encouragement and support. And lastly, but not least, my Father in Heaven for this wonderful opportunity. 


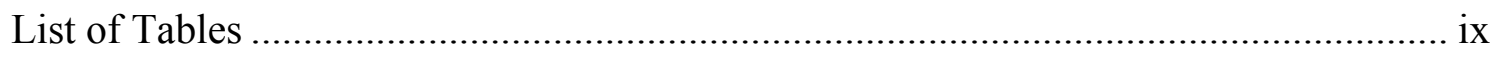

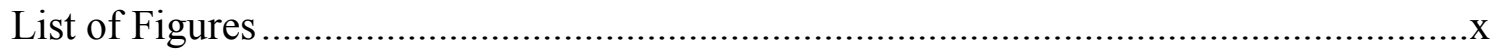

An Examination of Family Communication within the Core and Balance Model of Family Leisure Functioning

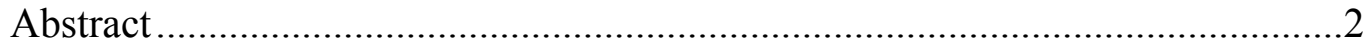

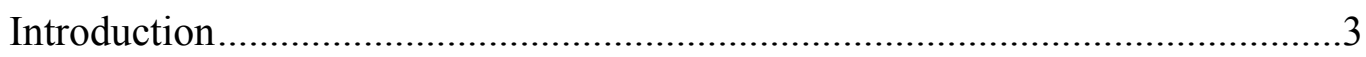

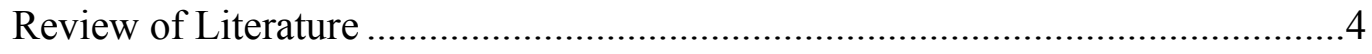

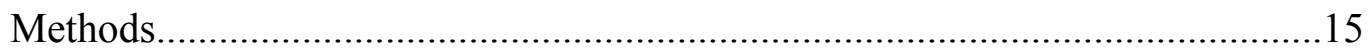

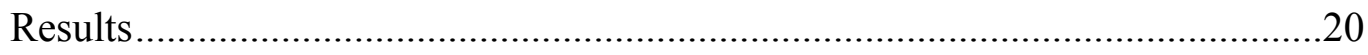

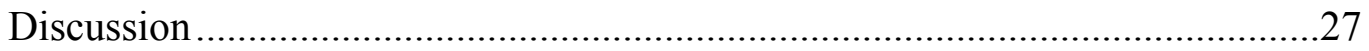

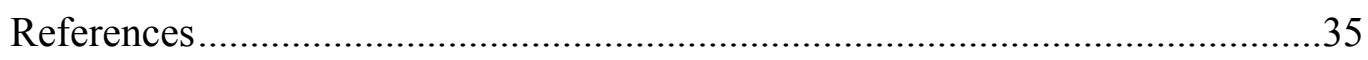

Appendix A Prospectus.........................................................................................52

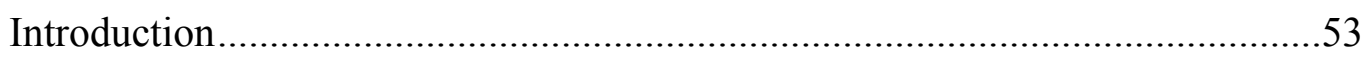

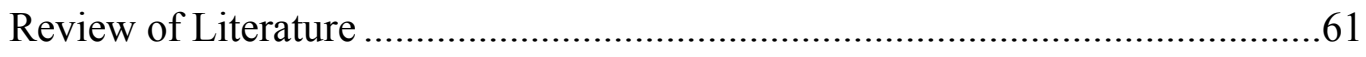

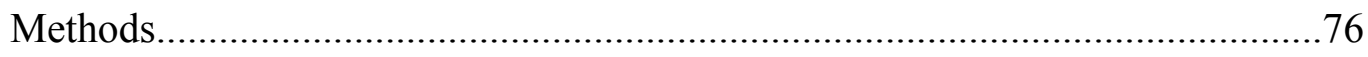

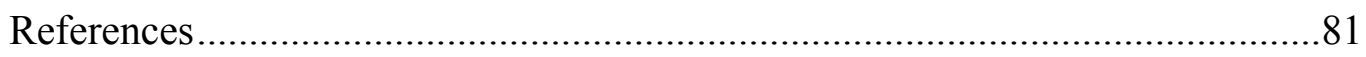

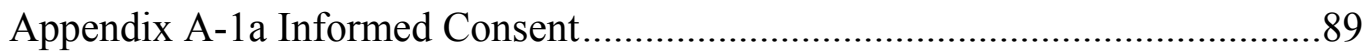

Appendix A-1b Family Leisure Activity Profile ……………………..................91

Appendix A-1c Family Adaptability and Cohesion Evaluation Scales II .........103

Appendix A-1d Family Communication Scale ...................................................105

Appendix A-1e Demographic Data ……………………….............................107 


\section{List of Tables}

Table

Page

1 Sample Means and Standard Deviations................................................. 43

2 Youth Sample Zero-Order Correlations...................................................... 44

3 Parent Sample Zero-Order Correlations ................................................. 45

4 Family Perspective Sample Zero-Order Correlations ................................. 46 


\section{List of Figures}

$\begin{array}{ll}\text { Figures } & \text { Page }\end{array}$

1 Olson's Family Circumplex Model .............................................................

2 Zabriskie's Core and Balance Model of Family Leisure Functioning..............48

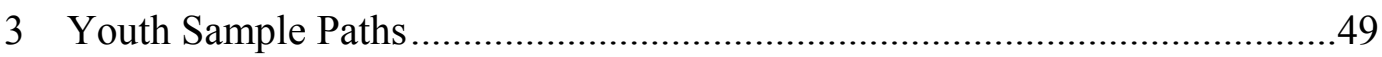

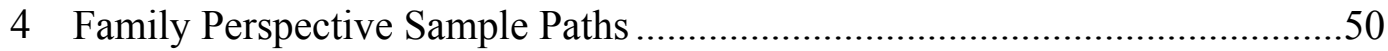

5 Revised Core and Balance Model of Family Leisure Functioning ...................51 
Leisure, Communication, and Family Functioning 1

Running head: LEISURE, COMMUNICATION, AND FAMILY FUNCTIONING

An Examination of Family Communication within the Core and Balance Model of Family Leisure Functioning

Kevin M. Smith

Brigham Young University 
2 Leisure, Communication, and Family Functioning

\begin{abstract}
The purpose of this study was to examine family communication within the Core and Balance Model of Family Leisure Functioning. This was accomplished using path analysis, specifically using a mediator model. Family leisure was measured using the Family Leisure Activity Profile (FLAP), family functioning using the Family Adaptability and Cohesion Evaluation Scales (FACES II), and family communication using the Family Communication Scale (FCS). The sample was youth $(\mathrm{n}=90)$ and parents $(\mathrm{n}=123)$ from 25 different states in the US. Family leisure involvement predicted family functioning variables from the youth and family perspectives, but only partially from the parent perspective. Family leisure also predicted family communication from the youth and family perspectives, but not from the parent perspective. Family communication predicted family functioning from all of the perspectives. Path analyses from the youth perspective indicated that the relationship between core family leisure and family flexibility was mediated by family communication, as well as the relationship between balance family leisure and family cohesion. Path analyses from the parent perspective indicated the same mediation by communication as the youth, with an addition of the mediation of the relationship between balance family leisure and family flexibility. The data indicated that family communication does mediate some of the relationship between family leisure involvement and family functioning.
\end{abstract}

Key Words: core, balance, Circumplex 
Leisure, Communication, and Family Functioning 3

Introduction

The Circumplex Model of Marital and Family Functioning is based on family systems theory and determines family functioning derived from indicators of cohesion, flexibility, and communication (Olson, 2000). Cohesion is defined as togetherness, or the emotional bonding a family shares, and flexibility is the ability to cope with change. Galvin and Brommel (1982) define communication as "a symbolic, transactional process, or the process of creating and sharing meanings" (p. 6). A family who has good family communication will be better able to alter their cohesion and flexibility to meet developmental and situational demands that arise (Olson \& Gorall, 2003). Furthermore, family systems with poor communication tend to have lower functioning in regard to cohesion and flexibility, whereas family systems with good communication tend function higher (Olson, 2000).

Zabriskie and McCormick (2001) developed the Core and Balance Model of Family Leisure Functioning. It is grounded in systems theory with particular focus on the Circumplex Model. Research using the Core and Balance Model has consistently found a positive relationship between family functioning and family leisure involvement (Christensen, 2004; Freeman \& Zabriskie, 2003; Smith, Taylor, Hill, \& Zabriskie, 2004; Zabriskie \& McCormick, 2001). These studies determined that aspects of family functioning (cohesion and flexibility) were related differently to core and balance family leisure activity patterns. Core family leisure includes those activities that are usually frequent, home-based, and low in cost, while balance family leisure includes those 
4 Leisure, Communication, and Family Functioning

activities that are novel, more challenging, and usually involve investment of time, effort, or money (Zabriskie \& McCormick, 2001).

The few studies that have examined the relationship between family leisure involvement and family communication have mostly focused on family adventure programs and their effect on family communication (Bandoroff \& Scherer, 1994; Huff, Widmer, McCoy, \& Hill, 2003; Kugath, 1997). There have been no studies, however, on general family leisure involvement and its relationship to family communication. Therefore, the purpose of this study was to examine the role of family communication in the Core and Balance Model, specifically to see if communication mediated the relationship between family leisure involvement and family functioning.

Review of Literature

\section{Systems Theory}

Systems theory is a paradigm that describes systems, or "sets of elements standing in interrelation among themselves and with the environment" (von Bertalanffy, 1975, p. 159). Three key assumptions found in systems theories are "that systems theories can unify science; that a system must be understood as a whole rather than in component parts; and that human systems are unique in their self-reflexivity" (Whitchurch \& Constantine, 1993, p. 328). Constantine (1986) defines a system as "a bounded set of interrelated elements exhibiting coherent behavior as a unit" (p. 50) and emphasizes the importance of not reducing the whole to solely examining its individual parts. He explains that the systems view is "characterized by its concern with wholes" and is "not reductionist. It does not attempt to explain wholes by reduction to simpler parts; rather, it 
understands parts by the functions they serve in the whole" (p. 49). Through psychiatry, systems theory entered family social science as families began to be viewed as systems (Whitchurch \& Constantine, 1993).

Family Systems Theory

The family is a complex system composed of individuals interacting with one another (Whitchurch \& Constantine, 1993). Rothbaum, Rosen, Ujiie, and Uchida (2002) posit that family systems theory is focused on family dynamics, which include structures, roles, communication patterns, boundaries, and power relations. Referring to Klein and White's (1996) work, Zabriskie and McCormick (2001) assert that family systems theory "holds that families are goal directed, self-correcting, dynamic, interconnected systems that both affect and are affected by their environment and by qualities within the family system itself”' (p. 281).

Like general systems theory, family systems theory views the whole of the family as greater than the sum of its parts. Fingerman and Bermann (2000) compared the family system to salt. The chemical composition of salt is a combination of sodium and chloride molecules. Upon contact with the end of the tongue, sodium, by itself, would explode while chloride would burn a hole through it. Yet together they form salt, which is not only harmless to the tongue, but is used to flavor food. While the members of a family are not necessarily volatile on their own, this comparison illustrates how the members of the family together are not just the sum of each member. Whitchurch and Constantine (1993) state that, "family processes can be understood as the product of the entire system, 
6 Leisure, Communication, and Family Functioning

shifting the primary focus away from the individual family member to relationships among the members of the family system" (p. 330).

Whitchurch and Constantine (1993) claim that systems theories can be used in understanding intrafamily processes, through transactions among the family, when the family is defined as a system. These processes include family functioning, family conflict, family communication and transactional patterns, cohesion, separateness and connectedness among members, integration, and adaptation to change. The Circumplex Model of Marital and Family Systems is based on family systems theory.

\section{Circumplex Model}

The Circumplex Model of Marital and Family Systems looks at the cohesion, flexibility, and communication of the family system. Olson and DeFrain (2000) described the Circumplex Model as "a graphic representation of dynamic relationships within families" (p. 66). The model emphasizes how family members and their behaviors are interconnected (see Figure 1).

The three dimensions in the Circumplex Model are cohesion (defined as togetherness), flexibility (defined as the ability to cope with change), and communication (Olson \& Gorall, 2003). Communication is not shown graphically in Figure 1, but it facilitates movement in a family between the extremes of the other two dimensions. Therefore, "if a couple or a family has good communication skills, they are more likely to be close (cohesion dimension) and to be able to work out problems (flexibility dimension) when they arise" (Olson \& Gorall, 2003, p. 66). Cohesion and flexibility are often used as indicators of family functioning (Olson \& Gorall, 2003). 
Family Cohesion. Cohesion in the family system is defined by Olson (2000) as "the emotional bonding that family members have toward one another" (p. 145). Cohesion focuses on how the members of the family system balance their separateness versus their togetherness (Olson, 2000). Olson and Gorall (2003) compared a family’s separateness versus their togetherness to the two legs of a skier:

Professional skiers keep their legs together and smoothly shift between their legs and the edges of the skis, creating a balance on separateness and togetherness. Similarly, balanced couples and families are also able to shift between being apart and being connected in a fluid manner. Conversely, novice skiers tend to keep their legs too far apart (too much separateness) or too close together (enmeshed), thereby creating an unbalanced system. Unbalanced couples and families also tend to be stuck at either extreme of separateness or togetherness and are unable to find a balance (p. 523).

Cohesion is separated into four different levels ranging from disengaged (very low cohesion), to separated (low to moderate), moving to connected (moderate to high), and ending at enmeshed (very high). Both disengaged and enmeshed levels of cohesion indicate an unbalanced relationship and can lead to problems for the family relationship. Relationships with separated and connected cohesion levels, however, have the ability to balance being alone versus being together in a more functional way (Olson, 2000).

Family Flexibility. Flexibility in the family system is defined by Olson (2000) as the "amount of change in its leadership, role relationships and relationship rules" ( $\mathrm{p}$. 147). Flexibility focuses on how family systems balance stability versus change (Olson, 
8 Leisure, Communication, and Family Functioning

2000). Olson and Gorall (2003) compared a family's balance of stability versus change to the body of a skier:

In watching professional skiers come down a ski slope, one sees fluidity in their movement left and right; they move their legs up and down to absorb the moguls while keeping the upper part of their body upright. In other words, there is both stability in the body and the ability to change. Likewise, in balanced couples and families, there is the ability not only to maintain stability but also to change, when necessary. Conversely, novice skiers tend to keep their body rigid; then, when they hit a mogul, they become even more rigid (unbalanced), which often results in a chaotic fall. Unbalanced couples and families also seem to be either too focuses on stability (leading to rigidity) or too open to change (leading to chaos) (p. 523).

Flexibility has four levels that range from rigid (very low), to structured (low to moderate), moving to flexible (moderate to high), and ending at chaotic (very high). Both rigid and chaotic levels of flexibility are unbalanced and can lead to problems for family relationship development. Relationships with flexible and structured flexibility levels, however, have the ability to balance stability and change in a more functional way (Olson, 2000).

A family who is unbalanced will have an extreme level of cohesion, at the disengaged or enmeshed level, and an extreme level of flexibility, at the rigid or chaotic level (Olson, 2000). A family who is balanced will have cohesion at the separated or connected level, and flexibility at the structured or flexible level, and will generally 
function better than unbalanced families. This balance of cohesion and flexibility is facilitated by family communication (Olson \& Gorall, 2003)

Family Communication. Family communication is the third dimension in the Circumplex Model (Olson, 2000). It acts as a process to make facts mutually manifest (Sperber \& Wilson, 1986) and develops and sustains reality in relationships (Berger \& Kellner, 1994). Communication has been defined "as a symbolic, transactional process, or to put it more simply, as the process of creating and sharing meanings" (Galvin \& Brommel, 1982, p. 6). The symbols in communication can come through a variety of forms. They can be verbal behavior, or words, and nonverbal behavior such as facial expressions, eye contact, gesture, movement, body posture, appearance, and spatial distance (Galvin \& Brommel, 1982).

Communication is the facilitative dimension in the Circumplex Model and helps a family alter their cohesion and flexibility to meet developmental and situational demands that arise (Olson \& Gorall, 2003). Olson (2000) stated that family systems with poor communication tend to be unbalanced, whereas family systems with good communication tend to be more balanced. Olson and Gorall (2003) also compared a family's communication to skiing:

Professional skiers are very much 'in touch' with all aspects of the hill, including the moguls and type of snow conditions, and they use this feedback to make good decisions. Likewise, balanced couples and families are open to communication and feedback from other sources, so that they can better adjust their levels of cohesion and flexibility. Conversely, novice skiers are often unaware of the 
10 Leisure, Communication, and Family Functioning

conditions of the hill or how to use that information. Lacking the feedback and information they need, they fail to improve their skiing. Unbalanced couples and families also ignore or are unable to accept feedback from others that could help them improve their ability to change their level of cohesion and flexibility (pp. $523-524)$.

Several studies support Olson's proposition that communication is a facilitator of family functioning (Anderson, 1986; Barnes \& Olson, 1985; Masselam, Marcus, \& Stunkard, 1990). Masselam et al. (1990) measured both family communication and family functioning with adolescents who had been unsuccessful in public school and were attending alternative schools, and compared them to the families with adolescents who were attending public school. They found that the adolescents in public school had higher levels of positive family communication and family functioning than did the adolescents in the alternative schools. This indicates that families who were balanced in terms of their cohesion and flexibility were more likely to have better family communication.

A study by Barnes and Olson (1985) also investigated the hypothesis that those families with balanced cohesion and flexibility would have better parent-adolescent communication. Their hypothesis was supported for the parents in their sample, but not for the children. When they combined the sample into a family perspective, they found that those families with good parent-adolescent communication were more likely to perceive their family balanced in cohesion and flexibility. Communication in the Circumplex model was also tested using instruments that were not developed by Olson in 
an effort to see if the model held true using instruments that were not created based purely on the Circumplex Model. Anderson's (1986) findings supported the Circumplex Model and found that positive communication skills were related to balanced cohesion and flexibility scores using different communication and family functioning measures.

In addition to examining the influence of family communication on family functioning several researchers have studied how family communication effects information processing in the home. Austin and Nelson (1993) posited that the family communication environment was a primary way through which cultural beliefs and customs can be shared. According to Austin, Roberts, and Nass (1990), parents directly affected children's opinions about matters close to home. Direct parental influences also tended to be greater for issues that were concrete as opposed to abstract (Jennings \& Niemi, 1968, 1974; Sears, 1975). Because a family relationship is intimate, misunderstanding in communication is likely to be more painful and have more serious consequences (Sieburg, 1985).

Good family communication skills have also been found to result in less serious forms of delinquency as well as lower rates of delinquency in adolescents (Clark \& Shields, 1997), the development of conflict resolution (Koerner \& Fitzpatrick, 1997), children's resiliency to adverse environmental influences (Fitzpatrick \& Koerner, 1996), and the enactment of family rituals (Baxter \& Clark, 1996). Good family communication skills have also been found to mitigate the effects of television on children (Krcmar, 1998), and increase the positive adjustment of cancer patients (Gotcher, 1993). On the other hand, poor family communication skills were found to result in a number of 
12 Leisure, Communication, and Family Functioning

problems for individuals, including shyness (Huang, 1999), communication apprehension (Elwood \& Schrader, 1998; Hsu, 1998), unwillingness to communicate (Avtgis, 2000), the development of reticence (Kelly et al., 2002), and delinquent behavior in adolescents (Clark \& Shields, 1997).

Positive communication is believed to facilitate the movement between cohesion and flexibility within the Circumplex Model; thus allowing families to function better in the face of various circumstances and change. Research has also shown that family cohesion and flexibility are related to two different kinds of family leisure patterns (Zabriskie \& McCormick, 2001).

\section{Leisure and Family Functioning}

Researchers have consistently found a positive relationship between family recreation and indicators of family functioning (Hawks, 1991; Holman \& Epperson, 1984; Orthner \& Mancini, 1991). Recent literature has looked specifically at the relationship between leisure and family functioning as defined by the balance between cohesion and flexibility (Christensen, 2004; Freeman \& Zabriskie, 2003; Smith et al., 2004; Zabriskie \& McCormick, 2001). These studies found a positive correlation between family leisure participation and family functioning. Furthermore, they found that aspects of family functioning were related differently to core and balance leisure patterns.

Core and Balance Model. The Core and Balance Model of Family Leisure Functioning is based on two types of leisure patterns, and the premise that leisure is used to facilitate stability and change in the family system. Zabriskie \& McCormick (2001) defined the two kinds of family leisure patterns as core and balance. Core family leisure 
activities are those that are easily accessible, common, often home-based, and low in cost. They are the activities that are commonplace in a person's life. These activities might include playing a game of catch, playing board games, or preparing and eating dinner as a family. Balance family leisure activities, in contrast, suggest variety. They are activities that are novel and participated in less frequently. These activities might include family vacations, traveling, outdoor activities, or going to a cultural event. Iso-Ahola (1984) states that individuals seek structure and variety, stability and change, and familiarity and novelty in their leisure behavior. Zabriskie and McCormick (2001) contend that similar to individuals, families also seek to balance these needs through their leisure behavior.

According to the model, core family leisure patterns address familiarity and stability in a family by regularly providing family leisure experiences that foster feelings of family closeness or cohesion. Conversely, balance family leisure patterns address novelty and change in a family by providing novel experiences that challenge families to negotiate and adapt to new input and to work together in a leisure context. Core family leisure activities, therefore, are theoretically related to the cohesion dimension of the Circumplex Model and balance family leisure activities are theoretically related to the flexibility dimension (see Figure 2) (Zabriskie \& McCormick, 2003).

Communication in Leisure Research. Although the relationship between family functioning and family leisure patterns has been investigated, little research has been conducted investigating family communication, the third dimension of the Circumplex Model, and leisure. Several individuals have hypothesized that outdoor recreation will 
14 Leisure, Communication, and Family Functioning

improve family communication (Gass, 1993; Orthner, Barnett-Morris, \& Mancini, 1994). This hypothesis has been supported by a few studies focused on family adventure programs (Bandoroff \& Scherer, 1994; Huff et al. 2003; Kugath, 1997).

Banderoff and Scherer (1994) found that families with problem adolescents who participated in a 21-day survival program reported improved communication within the family. Kugath (1997) discovered that fathers in families, who participated in an eighthour intensive family adventure program including rock climbing and white water rafting, had significant increases in their perceptions of family communication. Similarly, families in Huff et al's. (2003) study improved their level of parent-adolescent communication after a challenging family outdoor recreation experience.

Early research involving the Core and Balance Model recommended that the role of communication in the model be investigated. The role of family communication, however, has not been investigated to this date.

\section{Summary and Hypotheses}

Family Systems Theory uses the tenants of General Systems Theory to look at the family as a system, or as a whole (Whitchurch \& Constantine, 1993). The Circumplex Model of Marital and Family Systems is based on Family Systems Theory. The Circumplex Model addresses cohesion, flexibility, and communication within the family system. When family cohesion and flexibility are balanced families are more likely to function well. Communication is a dimension of the Circumplex Model that facilitates the movement of cohesion and flexibility (Olson, 2000). Leisure researchers have investigated leisure involvement and family functioning (Freeman \& Zabriskie, 2003; 
Smith et al., 2004; Zabriskie \& McCormick, 2001) as well as family adventure programs and family communication (Bandoroff \& Scherer, 1994; Huff et al. 2003; Kugath, 1997). Leisure researchers have not, however, investigated the role family communication plays in the relationship between family leisure and family functioning. Does family communication play a role in the relationship between family leisure involvement and family functioning? Based on this question, the following hypotheses were formed:

Hypothesis 1 . There is a positive relationship between family leisure involvement and family functioning.

Hypothesis 2. There is a positive relationship between family leisure involvement and family communication.

Hypothesis 3. There is a positive relationship between family communication and family functioning.

Hypothesis 4. Family communication is a significant mediator of the relationship between family leisure involvement and family functioning.

Methods

Sample

The participants were parents and youth from 25 different states around the US. They were recruited using a snowball convenience sample. The sample consisted of 90 youth and 123 parents. Youth ages ranged from 11 to 17 years of age with a mean age of $13.86(S D=1.45)$. The youth sample included $56 \%$ female and $44 \%$ male. Parent ages ranged from 20 to 68 with a mean age of $43.88(S D=7.51)$. The parent sample included $71 \%$ female and $29 \%$ male. Most parents were Caucasian (98\%) with the other $2 \%$ 
16 Leisure, Communication, and Family Functioning

Hispanic. Household incomes ranged from less than $\$ 10,000$ to over $\$ 150,000$ and $48 \%$ made less than $\$ 70,000$ while $52 \%$ made over $\$ 70,000$.

Procedures

Data were collected using an online survey that included all of the test instruments, from January 2005 until February 2005. The study participants were given the URL of the survey and asked to complete it on their own time. On the online survey's first page, participants were informed that participation in the study was voluntary and that they were allowed to stop at any time. It also stated that completing the questionnaire implied consent to participate in the study. This paragraph also stated that because there was no identifying information asked in the questionnaire, their participation was completely anonymous. Completed questionnaires were emailed to the principle investigator and stored in an online database.

\section{Instrumentation}

Three instruments were used for this study: the Family Adaptability and Cohesion Evaluation Scales (FACES II) (Olson, Portner, \& Bell, 1982), the Family Communication Scale (FCS) (Olson et al., 2004), and the Family Leisure Activity Profile (FLAP) (Zabriskie \& McCormick, 2001). Demographic questions were also asked.

FACES II is based on the Family System Circumplex Model (Olson, 2000). It was chosen over FACES III because it has been recommended that researchers use FACES II over FACES III because of its better psychometrics (Kinsman \& Wildman, 2001). FACES IV (Olson et al., 2004) was not used because it is a new measure that looks at family functioning in a curvilinear manner and would not, therefore, reflect past 
research on the Core and Balance Model, which have used linear scales. A linear scoring has been suggested by past research (Kinsman \& Wildman, 2001).

FACES II includes two scales, with 16 cohesion items and 14 flexibility items, for a total of 30 items. The 16 cohesion items included eight concepts, with two items for each concept, related to the cohesion dimensions of emotional bonding, family boundaries, coalitions, time, space, friends, decision-making, and interests and recreation. The 14 flexibility items included six concepts, with two or three items for each concept, related to the flexibility dimensions of assertiveness, leadership, discipline, negotiations, roles and rules (Olson et al., 1982).

The FACES II questions were measured on a five-point Likert scale, with one indicating "almost never" and five "almost always". A total score for both cohesion and flexibility was computed by summing the values for each (some items were reverse scored). Both scores were compared to a sliding scale that determined the "type" of cohesion and flexibility the family had. These types were scored from one to eight for both cohesion and flexibility, with one equaling "disengaged" for cohesion and "rigid" for flexibility and eight equaling "very connected" for cohesion and "very flexible" for flexibility. Adding the type scores of both cohesion and flexibility and dividing by two resulted in the family functioning score for the family. Olson et al. (1982) reported acceptable levels of internal consistency for two national samples $(\alpha=.88$ and $\alpha=.86$ for cohesion and $\alpha=.78$ and $\alpha=.79$ for flexibility). Internal consistency was tested in this study for the youth sample ( $\alpha=.65$ for cohesion and $\alpha=.83$ for flexibility) and parent sample ( $\alpha=.79$ for cohesion and $\alpha=.81$ for flexibility). 
18 Leisure, Communication, and Family Functioning

The Parent-Adolescent Communication Scale (PAC) has been used frequently to measure communication within families. The PAC is made up of two scales that measure the degree of openness in family communication and the extent of problems in family communication (Barnes \& Olson, 1985). The open communication subscale in the PAC measures the positive aspects of a family's communication and the problem communication subscale in the PAC measures the negative aspects of a family's communication.

As effective as the PAC was in measuring parent-adolescent communication, Olson, Gorall, and Tiesel (2004) recognized the need for a scale that could be used in a wider variety of circumstances. They also had seen interest in a shorter scale. Therefore, the Family Communication Scale (FCS) was developed and it was released as part of the FACES IV package (Olson et al., 2004).

The FCS consists of 10 questions. The 10 items were measured on a five-point Likert scale, with one describing the family "not at all" and five describing the family "very well". The total score indicated how functional the family communication was within the family. Olson et al. (2004) reported an acceptable level of internal consistency in a national sample for the scale $(\alpha=.88)$. Internal consistency was tested in this study for the youth sample $(\alpha=.92)$ and parent sample $(\alpha=.91)$.

The Family Leisure Activity Profile (FLAP) identifies and measures two types of family leisure patterns, core and balance. The FLAP included 16 questions. Eight of the questions were representative of core family leisure activities, and eight questions were representative of balance family leisure patterns. For each type of activity respondents 
specified if they do the activity with family members, and if so indicated the frequency and duration of participation. They then indicated how satisfied they were with their participation, or lack of participation, on a five-point Likert scale with one equaling "very dissatisfied" and five "very satisfied". Multiplying frequency by duration resulted in an index score for each question. The index scores for questions 1-8 were summed to calculate a core index score and questions 9-16 were summed for a balance index score. Summing the core and balance index scores created a total family leisure index score. Zabriskie and McCormick (2001) reported significant $(p<.01)$ test-retest correlations for core $(r=.74)$ and balance $(r=.78)$ family leisure indices with a five-week period between administrations in a college student sample. An international panel of experts ( $\mathrm{N}$ $=8$ ) confirmed evidence of content validity of the core and balance categories based on the theoretical model.

For parents, demographic questions included age, gender, ethnicity, religion, annual income, geographic location, and marital status and history. There were also questions about their family size and composition (i.e., number of children, children's ages, etc.) For youth, demographic questions included age and gender.

Analysis

In order to gain a family perspective of the data, the data were analyzed from a youth, parent, and family perspective. The family perspective was calculated using the mean score from paired parent and youth who came from the same family. Total scores were calculated for family communication, total family functioning, and total family leisure. Subscale scores were computed for family cohesion and family flexibility (scores 
20 Leisure, Communication, and Family Functioning

used to calculate total family functioning) as well family core and balance leisure activity patterns (sum equaled total family leisure). Zero-order correlations were calculated to check for multicollinearity and significant relationships among the research variables. Multiple regression equations were performed as part of the path analyses and to investigate the relationships among the variables.

Each path analysis was calculated using a 3-step process. The first step tested Hypothesis 1 by regressing the family functioning variable on the family leisure variable. The second step tested Hypothesis 2 by regressing family communication, the hypothesized mediator, on the family leisure variable. If the family leisure variable was a significant predictor of both the family functioning variable and family communication, the family functioning variable was regressed on both the family leisure variable and family functioning. This third step tested both Hypothesis 3 and 4. Family communication mediated the relationship between the family leisure variable and the family functioning variable if family communication was a significant predictor in the model and the family leisure variable was not.

Results

For each sample, a mean, standard deviation, minimum score, and maximum score were determined for each total and subscale score (see Table 1). The youth and family sample means were found to be similar to past samples using similar instrumentation (Freeman \& Zabriskie, 2003; Zabriskie, 2000). 
Leisure, Communication, and Family Functioning 21

\section{Zero-order Correlations}

Zero-order correlations were calculated to check for multicollinearity and significant relationships among the research variables. Multicollinearity was indicated by $r>.90$ (Tabachnick \& Fidell, 1996). Multicollinearity was not found between any of the research variables (see Tables $2,3, \& 4$ ) in any of the samples. For the youth sample, all research variables were significantly correlated (see Table 2). For the parent sample, only core family leisure patterns $(r=.229, p=.011)$ and total family leisure $(r=.183, p=$ .043) were positively correlated to family cohesion. Family communication was positively correlated to all family functioning variables (see Table 3 ). No other significant correlations were found. For the family mean sample, all research variables were significantly correlated (see Table 4).

\section{Path Analyses}

The results of the zero-order correlations guided the multiple regression analyses. Multiple regression analyses were computed to investigate the relationships between correlated variables at the multivariate level. Only those demographic variables that showed a significant relationship to the dependent variable were controlled for in each analysis (see Tables $2,3, \& 4$ ). No path analyses were calculated for the parent sample because the zero-order correlations were not significant between the family leisure variables and family communication.

Youth sample. Ordinary least squares regression was used to test the hypothesis that family communication mediated the relationship between core family leisure patterns and family cohesion. In order to ensure that there was a relationship to be mediated, 
22 Leisure, Communication, and Family Functioning

family cohesion was regressed on core family leisure patterns. Core was a significant predictor $(\beta=.57, p<.001)$ in a model that explained $32 \%\left(F_{1,88}=42.11 ; p<.001 ; \mathrm{N}=\right.$ 90) of the variance in family cohesion. In order to test for a significant relationship between core family leisure patterns and the hypothesized mediator, family communication, family communication was regressed on core. Core was a significant predictor $(\beta=.51, p<.001)$ in a model that accounted for $26 \%\left(F_{1,88}=30.84 ; p<.001 ; \mathrm{N}\right.$ $=90)$ of the variance in family communication. Since both core $(\beta=.23, p=.002)$ and family communication $(\beta=.66, p<.001)$ were significant variables in a model that explained $65 \%\left(F_{2,87}=78.86 ; p<.001 ; \mathrm{N}=90\right)$ of the variance in family cohesion, family communication was not a mediator of the relationship between core and family cohesion.

Ordinary least squares regression was used to test the hypothesis that family communication mediated the relationship between balance family leisure patterns and family flexibility. In order to ensure that there was a relationship to be mediated, family flexibility was regressed on balance. Balance was a significant predictor $(\beta=.47, p<$ $.001)$ in a model that explained $22 \%\left(F_{1,88}=24.87 ; p<.001 ; \mathrm{N}=90\right)$ of the variance in family flexibility. In order to test for a significant relationship between balance and the hypothesized mediator, family communication, family communication was regressed on balance. Balance was a significant predictor $(\beta=.45, p<.001)$ in a model that accounted for $20 \%\left(F_{1,88}=21.82 ; p<.001 ; \mathrm{N}=90\right)$ of the variance in family communication. Since both balance $(\beta=.17, p=.030)$ and family communication $(\beta=.67, p<.001)$ were significant variables in a model that explained $58 \%\left(F_{2,87}=58.91 ; p<.001 ; \mathrm{N}=90\right)$ of 
the variance in family flexibility, family communication was not a mediator of the relationship between balance and family flexibility.

Ordinary least squares regression was used to test the hypothesis that family communication mediated the relationship between core family leisure patterns and family flexibility. In order to ensure there was a relationship to be mediated, flexibility was regressed on core. Core was a significant predictor $(\beta=.47, p<.001)$ in a model that accounted for $22 \%\left(F_{1,88}=24.39 ; p<.001 ; \mathrm{N}=90\right)$ of the variance in flexibility. Since the relationship between core and family communication was established previously, flexibility was regressed on both core and communication to test for mediation. Since family communication was a significant predictor $(\beta=.68, p<.001)$ and core was not $(\beta$ $=.12, p=.155)$ in a model $\left(F_{2,87}=55.75 ; p<.001 ; \mathrm{N}=90\right)$ that accounted for $56 \%$ of the variance in family flexibility, the relationship between core and flexibility was mediated by family communication (see Figure 3 ).

Ordinary least squares regression was also used to test the hypothesis that family communication mediated the relationship between balance family leisure patterns and family cohesion. In order to ensure there was a relationship to be mediated, cohesion was regressed on balance. Balance was a significant predictor $(\beta=.37, p<.001)$ in a model that accounted for $14 \%\left(F_{1,88}=13.74 ; p<.001 ; \mathrm{N}=90\right)$ of the variance in cohesion. Since the relationship between balance and family communication was established previously, cohesion was regressed on both balance and communication to test for mediation. Since family communication was a significant predictor $(\beta=.77, p<.001)$ and balance was not $(\beta=.03, p=.728)$ in a model $\left(F_{2,87}=66.53 ; p<.001 ; \mathrm{N}=90\right)$ that 
24 Leisure, Communication, and Family Functioning

accounted for $61 \%$ of the variance in family cohesion, the relationship between balance and cohesion was mediated by family communication (see Figure 3).

Family perspective sample. Ordinary least squares regression was used to test the hypothesis that family communication mediated the relationship between total family leisure involvement and total family functioning. In order to ensure that there was a relationship to be mediated, family functioning was regressed on total family leisure. Total family leisure was a significant predictor $(\beta=.44, p=.001)$ in a model that explained $29 \%\left(F_{2,45}=9.07 ; p<.001 ; \mathrm{N}=48\right)$, of the variance in total family functioning. In order to test for a significant relationship between total family leisure and the hypothesized mediator, family communication, family communication was regressed on total family leisure. Total family leisure was a significant predictor $(\beta=.39, p=.007)$ in a model that accounted for $18 \%\left(F_{2,45}=4.83 ; p=.013 ; \mathrm{N}=48\right)$ of the variance in family communication. To test for mediation, total family functioning was regressed on both total family leisure and communication. Since family communication was a significant predictor $(\beta=.70, p<.001)$ and total family leisure was not $(\beta=.18, p=$ $.069)$ in a model $\left(F_{3,44}=33.32 ; p<.001 ; \mathrm{N}=48\right)$ that accounted for $69 \%$ of the variance in family functioning, the relationship between total family leisure and total family functioning was mediated by family communication (see Figure 4).

Ordinary least squares regression was used to test the hypothesis that family communication mediated the relationship between core family leisure patterns and family cohesion. In order to ensure that there was a relationship to be mediated, family cohesion was regressed on core. Core was a significant predictor $(\beta=.47, p=.001)$ in a model that 
explained $22 \%\left(F_{1,46}=13.25 ; p=.001 ; \mathrm{N}=48\right)$ of the variance in family cohesion. In order to test for a significant relationship between core and the hypothesized mediator, family communication, family communication was regressed on core. Core was a significant predictor $(\beta=.37, p=.006)$ in a model that accounted for $26 \%\left(F_{2,45}=7.85 ; p\right.$ $=.001 ; \mathrm{N}=48)$ of the variance in family communication. To test for mediation, cohesion was regressed on both core and communication. Since both core $(\beta=.22, p=.023)$ and family communication $(\beta=.70, p=<.001)$ were significant variables in a model that explained $65 \%\left(F_{2,45}=41.14 ; p<.001 ; \mathrm{N}=48\right)$ of the variance in family cohesion, family communication was not a mediator of the relationship between core and family cohesion.

Ordinary least squares regression was used to test the hypothesis that family communication mediated the relationship between balance family leisure patterns and family flexibility. In order to ensure that there was a relationship to be mediated, family flexibility was regressed on balance. Balance was a significant predictor $(\beta=.33, p=$ $.017)$ in a model that explained $21 \%\left(F_{2,45}=5.87 ; p=.005 ; \mathrm{N}=48\right)$ of the variance in family flexibility. In order to test for a significant relationship between balance and the hypothesized mediator, family communication, family communication was regressed on balance. Balance was a significant predictor $(\beta=.36, p=.013)$ in a model that accounted for $13 \%\left(F_{1,46}=6.75 ; p=.013 ; \mathrm{N}=48\right)$ of the variance in family communication. To test for mediation, flexibility was regressed on both balance and communication. Since family communication was a significant predictor $(\beta=.57, p<.001)$ and balance was not $(\beta=.14, p=.244)$ in a model $\left(F_{3,44}=13.79 ; p<.001 ; \mathrm{N}=48\right)$ that accounted for $69 \%$ of 
26 Leisure, Communication, and Family Functioning

the variance in family flexibility, the relationship between balance and flexibility was mediated by family communication (see Figure 4).

Ordinary least squares regression was used to test the hypothesis that family communication mediated the relationship between core family leisure patterns and family flexibility. In order to ensure there was a relationship to be mediated, flexibility was regressed on core. Core was a significant predictor $(\beta=.38, p=.004)$ in a model that accounted for $27 \%\left(F_{3,44}=7.93 ; p<.001 ; \mathrm{N}=48\right)$ of the variance in flexibility. Since the relationship between core and family communication was established previously, flexibility was regressed on both core and communication to test for mediation. Since family communication was a significant predictor $(\beta=.49, p<.001)$ and core was not $(\beta$ $=.21, p=.077)$ in a model $\left(F_{4,43}=11.56 ; p<.001 ; \mathrm{N}=48\right)$ that accounted for $52 \%$ of the variance in family flexibility, the relationship between core and flexibility was mediated by family communication (see Figure 4).

Ordinary least squares regression was also used to test the hypothesis that family communication mediated the relationship between balance family leisure patterns and family cohesion. In order to ensure there was a relationship to be mediated, cohesion was regressed on balance. Balance was a significant predictor $(\beta=.31, p=.024)$ in a model that accounted for $11 \%\left(F_{1,46}=5.44 ; p=.024 ; \mathrm{N}=48\right)$ of the variance in cohesion. Since the relationship between balance and family communication was established previously, cohesion was regressed on both balance and communication to test for mediation. Since family communication was a significant predictor $(\beta=.76, p<.001)$ and balance was not $(\beta=.05, p=.591)$ in a model $\left(F_{3,44}=34.53 ; p<.001 ; \mathrm{N}=48\right)$ that accounted for $61 \%$ of 
the variance in family cohesion, the relationship between balance and flexibility was mediated by family communication (see Figure 4).

\section{Discussion}

Findings indicated support for the first hypothesis, that family leisure involvement was related to family functioning, particularly from the youth and family perspectives. The second hypothesis, that family leisure involvement was related to family communication, was also supported from the youth and family perspectives, but not from the parent perspective. All three perspectives supported the third hypothesis, that family communication was related to family functioning. Findings from the youth and family perspectives partially supported the fourth hypothesis, that family communication mediates the relationship between family leisure involvement and family functioning.

Regarding the first hypothesis, total family leisure involvement significantly predicted total family functioning from the youth $(\beta=.54)$ and family $(\beta=.44)$ perspectives, including significant relationships between each family leisure variable (core and balance) and each family functioning variable (cohesion and flexibility). Core family leisure was a stronger predictor of family cohesion than balance family leisure in both the youth sample (balance $\beta=.37$; core, $\beta=.57$ ) and the family sample (balance, $\beta$ $=.33$; core, $\beta=.47$ ). From the parent perspective, however, only core was related to family cohesion $(\beta=.21)$. These findings support previous research (Freeman $\&$ Zabriskie, 2003; Smith et al., 2004; Zabriskie \& McCormick, 2001) that also found core family leisure to be a stronger predictor of family cohesion than family flexibility. Such 
28 Leisure, Communication, and Family Functioning

findings strengthen the assertion of the Core and Balance Model that core family leisure activities lead to outcomes of family cohesion.

Both balance and core family leisure patterns were equally strong predictors of family flexibility from the youth perspective (balance, $\beta=.47$; core, $\beta=.47$ ). This is consistent with previous findings (Freeman \& Zabriskie, 2003; Smith, et al., 2004; Zabriskie \& McCormick, 2001) that found both core and balance to similarly predict family flexibility. Surprisingly, from the family perspective core was a stronger predictor of family flexibility $(\beta=.38)$ than balance $(\beta=.33)$, which differs from the previous findings (Freeman \& Zabriskie, 2003; Smith, et al., 2004; Zabriskie \& McCormick, 2001). The current findings suggest that common, home-based, low-cost, and relatively accessible family activities (core)have more influence for family functioning than in frequent, out of the ordinary, and costly activities (balance). This is heartening for family structures that often struggle with time and money issues like lower income and singleparent families (Weitoft, Hjern, Haglund \& Rosen, 2003).

Overall, findings from the first hypothesis indicate that core family leisure activities were a stronger predictor of family functioning than balance family leisure activities. This provides further support to Freeman and Zabriskie's (2004) claim that core family leisure activities are "essential to higher family functioning and may make a more valuable contribution to family life" (p. 90).Similarly, Shaw and Dawson (2001) interviewed parents and found that they valued participating in family leisure time with their children for several reasons. They saw family leisure as a way to help foster family cohesion. The importance that the parents in their study placed on simply spending time 
with their children suggested that core kinds of family leisure activities were important for their families. This is reminiscent to the relationship found between core family leisure activities and family cohesion.

Family leisure involvement significantly predicted family communication (Hypothesis 2 ) from both the youth (total leisure, $\beta=.52$; core, $\beta=.51$; balance, $\beta=.47$ ) and family perspectives (total leisure, $\beta=.39$; core, $\beta=.37$, balance, $\beta=.37$ ), but not from the parent perspective. These findings indicate that while family leisure involvement may not predict a positive change in family communication for the parents, the relationship between family leisure involvement and family communication from the youth perspective made a significant difference for the family perspective. It is likely that for the youth, family leisure is one of the primary contexts for positive communication with their parents. In today's society opportunity for parent-child communication is often limited to family crises, youth discipline, and brief conversations in passing. Therefore, family leisure can provide a supportive context and a comfortable medium that facilitates parent and youth interaction and communication.

The lack of a relationship found between family leisure involvement and family communication from the parent perspective was surprising. Shaw and Dawson (2001) found that the parents in their sample stated an improvement in family communication as one of the reasons they participated in family leisure. This difference may be explained by the fact that Shaw and Dawson (2001) focused on the parent's interaction with their children and this study focused on family interaction in general. This suggests that there may be a difference in perceptions of family communication depending on individual 
30 Leisure, Communication, and Family Functioning

family member's perspectives. There also may have been a difference between the parents and youth of this sample because of the level of communication needs for the individuals. The youth may have felt satisfied with the level of communication with their parents, whereas the parents saw it as insufficient. In regards to the third hypothesis, that family communication is related to family functioning, the zero-order correlations between indicators of family communication and family functioning were significant from all three perspectives (see Tables 2, 3, \& 4). All regression models that regressed family functioning variables on family communication found family communication to be a significant predictor of family functioning variables (see Figures $3 \& 4$ ). This supports the findings of Masselam et al. (1990) in relation to family communication being a significant predictor of family functioning. In contrast to the findings of Barnes and Olson (1985), whose youth did not show a significant prediction while the parents did, the youth and parents of this sample both showed similar prediction. Therefore, these findings support the assertion of the Circumplex Model that those families with better family communication will have higher functioning in terms of their family cohesion and flexibility. This implies that a variable that influences a change in family communication may, as a result, have an influence on family functioning.

Testing the fourth hypothesis showed mixed results. From the youth perspective, two path analyses found significant mediation between the family leisure variable and the family functioning variable (see Figure 3) by family communication. Interestingly, core family leisure activities were related to flexibility through the influence of family 
communication and balance family leisure activities were related to cohesion also through the influence of family communication.

The basic premise of the Core and Balance Model was also supported, in that core family leisure activities predicted a change in family cohesion and balance family leisure activities predicted a change in family flexibility. These path analyses suggest that from the youth perspective, core family leisure activities have a direct influence on family cohesion, and they also have an indirect influence on family flexibility through family communication. Likewise, balance family leisure activities seem to have a direct influence on family flexibility, and an influence on family cohesion through family communication. This helps explain the way core and balance family leisure patterns have been related to family cohesion and flexibility in slightly different ways in past studies (Freeman \& Zabriskie, 2003; Smith et al., 2004; Zabriskie \& McCormick, 2001). Current findings provide additional insight into the interrelationship between core and balance family leisure patterns and their overall contribution to both aspects of family functioning.

The family perspective sample had three path analyses that showed significant mediation of the relationship between the family leisure variable and the family functioning variable (see Figure 4) by family communication. In addition to the paths found in the youth sample, family communication mediated the relationship between balance family leisure activities and family flexibility. This is relatively consistent with the findings from the youth perspective. The additional mediation of the relationship between balance and flexibility suggests that from the family perspective, the influence 
32 Leisure, Communication, and Family Functioning

of balance family leisure on flexibility came primarily through the medium of family communication.

The differences found between the family and youth perspectives are noteworthy. While there was the additional mediation of the relationship between balance family leisure activities and family flexibility by family communication from the family perspective, the relationship between core family leisure activities and family cohesion held true from both the youth and family perspectives. This further supports the importance of core family leisure activities for strong functioning families.

It also needs to be noted that the family perspective came from a mean score of the youth and parents. Because there were some differences between the youth and parent perspectives, the mean score is limited in that it removes extreme scores. Green and Vosler (1992) caution that using a family mean score may "obscure differences among family members" (p. 16).

\section{Implications/ Recommendations}

Overall, findings not only provide further supportive evidence of the Core and Balance Model of Family Functioning, but also suggest a possible addition. For the most part, the influence of core on cohesion was supported, as well as the influence of balance on flexibility. However, the path analyses advocate the addition of family communication as another factor in the model. The influence of family leisure involvement on family functioning appeared to be mediated, to a degree, by family communication. The proposed revision of the Core and Balance Model includes family communication in a mediating role (see Figure 5). The revised Core and Balance Model includes family 
communication as a mediating construct that is positioned between family leisure and family functioning. The model still shows the direct relationship between of core and cohesion and the relationship between balance and flexibility, but also indicates that both core and balance can influence cohesion and flexibility through family communication.

The addition of increased communication in the Core and Balance Model has a variety of implications for families and those who work with them. Professionals working with families on communication skills should acknowledge family leisure as a primary context in home life in which communication occurs. Therefore, the use of leisure modalities are likely to provide positive treatment for communication skills. Furthermore, parents should also be aware of the context in which communication takes place within the home or with family. Parents can purposefully plan for family time that affords communication in a leisure setting (see Shaw \& Dawson, 2001).

This study is the first step to examine communication and its role in the Core and Balance Model. While research has supported the hypotheses of the Core and Balance Model, some of the findings suggest that there is still much to discover. It is suggested that further research explore the discrepancies found between the youth and parents in this sample in further detail by sampling more youth and parents who come from the same family. It is recommended that family communication be included in future studies that investigate the relationship between family leisure involvement and family functioning to further explore the role communication plays in the Core and Balance Model. In addition, it is recommended that researchers also take additional samples from 
34 Leisure, Communication, and Family Functioning

different family types to see if the hypotheses supported in this sample are supported for different family circumstances. 
Leisure, Communication, and Family Functioning 35

\section{References}

Amerikaner, M., Monks, G., Wolfe, P., \& Thomas, S. (1994). Family interaction and individual psychological health. Journal of Counseling \& Development, 72, 614620.

Anderson, S. A. (1986). Cohesion, flexibility, and communication: A test of an Olson circumplex model. Family Relations, 35, 289-293.

Austin, E. W., \& Nelson, C. L. (1993). Influences of ethnicity, family communication and media on adolescents' socialization to U.S. politics. Journal of Broadcasting \& Electronic Media, 37(4), 419-436.

Austin, E. W., Roberts, D. F., \& Nass, C. I. (1990). Influences of family communication on children's television interpretation processes. Communication Research, 17, $545-564$.

Avtgis, T. A. (2000). The relationship between unwillingness to communicate and family communication patterns. Communication Research Reports, 16, 333-338.

Bandoroff, S., \& Scherer, D. G. (1994). Wilderness family therapy: An innovative treatment approach for problem youth. Journal of Child and Family Studies, 3(2), $175-191$.

Barnes, H. L., \& Olson, D. H. (1985). Parent-adolescent communication and the circumplex model. Child Development, 56, 438-447.

Baxter, L. A., \& Clark, C. L. (1996). Perceptions of family communication patterns and the enactment of family rituals. Western Journal of Communication, 60, 254-268. 
36 Leisure, Communication, and Family Functioning

Berger, P., \& Kellner, H. (1994). Marriage and the construction of reality: An exercise in the microsociology of knowledge. In G. Handel \& G. G. Whitchurch (Eds.), The psychosocial interior of the family (4th ed.; pp. 19-36). New York: Aldine De Gruyter.

Brage, D. \& Meredith, W. (1994). A causal model of adolescent depression. The Journal of Psychology, 128(4), 455-468.

Brown, J. E., \& Mann, L. (1990). The relationship between family structure and process variables and adolescent decision making. Journal of Adolescence, 13, 25-37.

Callahan, C. M., Cornell, D. G., \& Loyd, B. (1990). Perceived competence and parentadolescent communication in high ability adolescent females. Journal for the Education of the Gifted, 13(3), 256-269.

Christensen, O. D. (2004). An examination of perceptions for family acculturation, family leisure involvement, and family functioning among Mexican-Americans. Unpublished master's thesis, Brigham Young University, Provo, Utah.

Clark, R. D., \& Shields, G. (1997). Family communication and delinquency. Adolescence, 32, 81-93.

Constantine, L. L. (1986). Systems in general: Basic general systems theory. In L. L. Constantine (Ed.), Family paradigms: The practice of theory in family therapy (pp. 45-67). New York: Guilford.

Elwood, T. D., \& Schrader, D. C. (1998). Family communication patterns and communication apprehension. Journal of Social Behavior \& Personality, 13, 493502. 
Feldman, S. S., Rubenstein, J. L., \& Rubin, C. (1988). Depressive affect and restraint in early adolescents: Relationships with family structure, family process and friendship support. Journal of Early Adolescence, 8(3), 279-296.

Fingerman, K. L., \& Bermann, E. (2000). Applications of family systems theory to the study of adulthood. International Journal of Aging and Human Development, 51(1), 5-29.

Fitzpatrick, M. A., \& Koerner, A. F. (1996). Family communication schemata and social functions of communication. Paper presented at the International Research Colloquium on Communication Research, Moscow, Russia.

Freeman, P., \& Zabriskie, R. B. (2003). Leisure and family functioning in adoptive families: Implications for therapeutic recreation. Therapeutic Recreation Journal, 37(1), 73-93.

Galvin, K. M., \& Brommel, B. J. (1982). Family communication: Cohesion and change. Glenview, IL: Scott, Foresman and Company.

Gass, M. A. (1993). Adventure therapy: Therapeutic applications of adventure programming. Dubuque, IA: Dendall/Hunt Publishing Company.

Green R. G., \& Vosler, N. R. (1992). Issues in the assessment of family practice: An empirical study. Journal of Social Service Research, 15(3/4), 1-19.

Gotcher, J. M. (1993). The effects of family communication on psychosocial adjustment of cancer patients. Journal of Applied Communication Research, 21(2), 176-188.

Hawks, S. R. (1991). Recreation in the family. In S. J. Bahr (Ed.), Family research: A sixty year review, 1930-1990 (pp. 387-433). New York: Lexington Books. 
38 Leisure, Communication, and Family Functioning

Henry, C. S., \& Lovelace, S. G. (1995). Family resources and adolescent family life satisfaction in remarried family households. Journal of Family Issues, 16(6), 765 786.

Holman, T. B., \& Epperson, A. (1984). Family and leisure: A review of the literature with research recommendations. Journal of Leisure Research, 16, 277-294.

Hsu, C. F. (1998). Relationships between family characteristics and communication apprehension. Communication Research Reports, 15, 91-98.

Huang, L. N. (1999). Family communication patterns and personality characteristics. Communication Quarterly, 47, 230-243.

Huff, C., Widmer, M., McCoy, K., \& Hill, B. (2003). The influence of challenging outdoor recreation on parent-adolescent communication. Therapeutic Recreation Journal, 37(1), 18-37.

Iso-Ahola, S. E. (1984). Social psychological foundations of leisure and resultant implications for leisure counseling. In E. T. Dowd (Ed.), Leisure counseling: Concepts and applications (pp. 97-125). Springfield, IL: Charles C. Thomas.

Jennings, M. K., \& Niemi, R. G. (1968). The transmission of political values from parent to child. American Political Science Review, 62, 169-184.

Jennings, M. K., \& Niemi, R. G. (1974). The political character of adolescence. Princeton: Princeton University Press.

Kelly, J. R. (1999). Leisure behaviors and styles: Social, economic, and cultural factors. In E. L. Jackson \& T. L. Burton (Eds.), Leisure Studies: Prospects for the TwentyFirst Century (pp. 135-150). State College, PA: Venture. 
Kelly, L., Keaten, J. A., Finch, C., Duarte, I. B., Hoffman, P., \& Michels, M. M. (2002). Family communication patterns and the development of reticence. Communication Education, 51(2), 202-209.

Kinsman, A. M., \& Wildman, B. G. (2001). Mother and child perceptions of child functioning: Relationship to maternal distress. Family Process, 40(2), 163-172

Klein, D. M., \& White, J. M. (1996). Family theories: An introduction. Thousand Oaks, CA: Sage.

Koerner, A. F., \& Fitzpatrick, M. A. (1997). Family type and conflict: The impact of conversation orientation and conformity orientation on conflict in the family. Communication Studies, 48, 59-78.

Kouneski, E. F. (2000). Family assessment and the circumplex model: New research developments and applications. Unpublished manuscript, University of Minnesota at St. Paul, MN.

Krcmar, M. (1998). The contribution of family communication patterns to children interpretations of television violence. Journal of Broadcasting \& Electronic Media, 42(2), 250-265.

Kugath, S. (1997). The effects of family participation in outdoor adventure programs. Unpublished doctoral dissertation, Indiana University, Indiana.

Masselam, V. S., Marcus, R. F., \& Stunkard, C. L. (1990). Parent-adolescent communication, family functioning, and school performance. Family Therapy, 27(2), 177-189. 
40 Leisure, Communication, and Family Functioning

Olson, D. H. (2000). Circumplex Model of Marital and Family Systems. Journal of Family Therapy, 22(2), 144-167.

Olson, D. H., \& DeFrain, J. (2000). Marriage and the family: Diversity and strengths, (pp. 66-97). Mountain View, CA: Mayfield.

Olson, D. H., \& Gorall, D. M. (2003). Circumplex model of marital and family systems. In F. Walsh (Ed.) Normal Family Processes (3rd ed, pp. 514-547). New York: Guilford.

Olson, D. H., Gorall, D. M., \& Tiesel, J. W. (2004). Faces IV Package. Minneapolis, MN: Life Innovations.

Olson, D. H., Portner, J., and Bell, R. (1982). FACES II: Family adaptability and cohesion evaluation scales. St. Paul, MN: Family Social Science, University of Minnesota.

Orthner, D. K., Barnett-Morris, L., \& Mancini, J. A. (1994). Leisure and family over the life cycle. Handbook of Developmental Family Psychology \& Psychopathology, (pp. 176-201), New York: John Wiley \& Sons.

Orthner, D. K., \& Mancini, J. A. (1991). Benefits of leisure for family bonding. In B. L. Driver, P. J. Brown, \& G. L. Peterson (Eds.), Benefits of leisure (pp. 215-301). State College, PA: Venture.

Papini, D. R., Farmer, F. F., Clark, S. M., Micka, J. C., \& Barnett, J. K. (1990). Early adolescent age and gender differences in patterns of emotional self-disclosure to parents and friends. Adolescence, 25, 959-976. 
Rothbaum, F., Rosen, K., Ujiie, T., \& Uchida, N. (2002). Family systems theory, attachment theory, and culture. Family Process, 41, 328-350.

Sears, D. O. (1975). Political socialization. In F. I. Greenstein \& N. W. Polsby (Eds.), Handbook of political science (Vol. 2): Micropolitical theory (pp. 93-153). Reading, MA: Addison-Wesley.

Sieburg, E. (1985). Family communication: An integrated systems approach. New York: Gardner Press.

Smith, K. M., Taylor, S., Hill, B., \& Zabriskie, R. B. (2004). Family functioning and leisure in single-parent families. Abstracts from the 2004 Leisure Research Symposium. Ashburn, VA: National Recreation and Parks Association.

Sperber, D., \& Wilson, D. (1986). Relevance: Communication and cognition. Cambridge, MA: Harvard University Press.

Tabachnick, B. G., \& Fidell, L. S. (1996). Using multivariate statistics ( $3^{\text {rd }}$ ed). New York: HarperCollins College Publishers.

von Bertalanffy, L. (1975). Perspectives on general systems theory: Scientificphilosophical studies. New York: George Braziller.

Whitchurch, G. G., \& Constantine, L. L. (1993). Systems theory. In P. G. Boss, W. J. Doherty, R. LaRossa, W. R. Schumm, \& S. K. Steinmetz (Eds.), Sourcebook of family theories and methods: A contextual approach (pp. 325-349). New York: Plenum Press. 
42 Leisure, Communication, and Family Functioning

Weitoft, G. R., Hjern, A., Haglund, B., \& Rosen, M. (2003). Mortality, severe morbidity, and injury in children living with single parents in Sweden: A population-based study. Lancet, 361, 289-295.

Zabriskie, R. B. (2000). An examination of family and leisure behavior among families with middle school aged children. Unpublished doctoral dissertation, Indiana University, Bloomington, Indiana.

Zabriskie, R. B., \& McCormick, B. P. (2001). The influences of family leisure patterns on perceptions of family functioning. Family Relations, 50, 281-289.

Zabriskie, R. B., \& McCormick, B. P. (2003). Parent and child perspectives of family leisure involvement and satisfaction with family life. Journal of Leisure Research, 35(2), 163-189. 
Table 1

Sample Means and Standard Deviations

\begin{tabular}{|c|c|c|c|c|}
\hline Variable & M & SD & Min & Max \\
\hline \multicolumn{5}{|l|}{ Youth Sample $(n=90)$} \\
\hline Family Communication & 35.37 & 8.99 & 10.00 & 50.00 \\
\hline Family Cohesion & 57.61 & 10.70 & 29.00 & 76.00 \\
\hline Family Flexibility & 46.00 & 9.72 & 20.00 & 64.00 \\
\hline Family Functioning & 4.43 & 1.69 & 1.00 & 7.50 \\
\hline Core FLP* & 40.28 & 17.50 & 4.00 & 107.00 \\
\hline Balance FLP & 64.52 & 34.66 & 0.00 & 187.00 \\
\hline Total Family Leisure & 104.80 & 46.89 & 4.00 & 255.00 \\
\hline \multicolumn{5}{|l|}{ Parent Sample $(n=123)$} \\
\hline Family Communication & 38.49 & 6.22 & 18.00 & 50.00 \\
\hline Family Cohesion & 64.69 & 8.64 & 33.00 & 78.00 \\
\hline Family Flexibility & 48.94 & 6.53 & 23.00 & 63.00 \\
\hline Family Functioning & 5.39 & 1.35 & 1.00 & 7.50 \\
\hline Core FLP & 44.58 & 12.55 & 9.00 & 81.00 \\
\hline Balance FLP & 63.79 & 24.84 & 0.00 & 148.00 \\
\hline Total Family Leisure & 108.37 & 32.10 & 9.00 & 195.00 \\
\hline \multicolumn{5}{|c|}{ Family Perspective Sample $(n=48)$} \\
\hline Family Communication & 38.49 & 6.22 & 25.00 & 48.00 \\
\hline Family Cohesion & 64.69 & 8.64 & 38.00 & 77.00 \\
\hline Family Flexibility & 48.94 & 6.53 & 36.00 & 58.00 \\
\hline Family Functioning & 5.39 & 1.35 & 1.75 & 7.50 \\
\hline Core FLP & 44.58 & 12.55 & 8.00 & 84.00 \\
\hline Balance FLP & 63.79 & 24.84 & 0.00 & 128.00 \\
\hline Total Family Leisure & 108.37 & 32.10 & 8.00 & 173.00 \\
\hline
\end{tabular}

Note: ${ }^{*}$ FLP $=$ Family Leisure Patterns 
44 Leisure, Communication, and Family Functioning

Table 2

Youth Sample Zero-Order Correlations

\begin{tabular}{|c|c|c|c|c|c|c|c|}
\hline & Leisure & Core & Balance & Functioning & Cohesion & Flexibility & Comm. \\
\hline Leisure & 1 & $.795 *$ & $.952 *$ & $.536^{*}$ & $.484 *$ & $.521 *$ & $.520 *$ \\
\hline Core & & 1 & $.570^{*}$ & $.533^{*}$ & $.569 *$ & $.466^{*}$ & $.509 *$ \\
\hline Balance & & & 1 & $.456^{*}$ & $.368 *$ & $.469 *$ & $.446^{*}$ \\
\hline Functioning & & & & 1 & $.872 *$ & $.892 *$ & $.784 *$ \\
\hline Cohesion & & & & & 1 & $.658 *$ & $.777 *$ \\
\hline Flexibility & & & & & & 1 & $.743 *$ \\
\hline Comm. & & & & & & & 1 \\
\hline
\end{tabular}

Note: ${ }^{*} p<$ 
Table 3

Parent Sample Zero-Order Correlations

\begin{tabular}{|c|c|c|c|c|c|c|c|c|c|}
\hline & Leisure & Core & Balance & Functioning & Cohesion & Flexibility & Comm. & Ethnicity & Income \\
\hline Leisure & 1 & $.709 * *$ & $.934 * *$ & .132 & $.183^{*}$ & .081 & .028 & .051 & .168 \\
\hline Core & & 1 & $.411^{* *}$ & .147 & $.229^{*}$ & .068 & .064 & $.191 *$ & -.003 \\
\hline Balance & & & 1 & .096 & .121 & .070 & .004 & -.031 & $.219 *$ \\
\hline Functioning & & & & 1 & $.918 * *$ & $.835 * *$ & $.821 * *$ & .111 & -.006 \\
\hline Cohesion & & & & & 1 & $.623 * *$ & $.782 * *$ & .128 & .048 \\
\hline Flexibility & & & & & & 1 & $.729 * *$ & .155 & -.069 \\
\hline Comm. & & & & & & & 1 & .115 & -.045 \\
\hline Ethnicity & & & & & & & & 1 & .043 \\
\hline Income & & & & & & & & & 1 \\
\hline
\end{tabular}

Note: $* p<0.05$

Note: $* * p<0.01$ 
46 Leisure, Communication, and Family Functioning

Table 4

Family Perspective Sample Zero-Order Correlations

\begin{tabular}{|c|c|c|c|c|c|c|c|c|c|c|}
\hline & Leisure & Core & Balance & Functioning & Cohesion & Flexibility & Comm. & Income & $\begin{array}{c}\text { Parent } \\
\text { Age }\end{array}$ & $\begin{array}{c}\text { Youth } \\
\text { Age }\end{array}$ \\
\hline Leisure & 1 & $.756 * *$ & $.947 * *$ & $.483 * *$ & $.423 * *$ & $.434 * *$ & $.405 * *$ & .203 & .017 & .172 \\
\hline Core & & 1 & $.504 * *$ & $.483 * *$ & $.473 * *$ & $.416^{* *}$ & $.358^{*}$ & -.041 & $-.338 *$ & .182 \\
\hline Balance & & & 1 & $.399 * *$ & $.325^{*}$ & $.368^{*}$ & $.358 *$ & $.288^{*}$ & .189 & .137 \\
\hline Functioning & & & & 1 & $.894 * *$ & $.880 * *$ & $.801^{* *}$ & .268 & -.160 & $.313^{*}$ \\
\hline Cohesion & & & & & 1 & $.620 * *$ & $.776^{* *}$ & .152 & -.253 & .247 \\
\hline Flexibility & & & & & & 1 & $.654 * *$ & $.287^{*}$ & -.086 & $.316^{*}$ \\
\hline Comm. & & & & & & & 1 & $.346^{*}$ & -.031 & .181 \\
\hline Income & & & & & & & & 1 & $.286^{*}$ & -.154 \\
\hline Parent Age & & & & & & & & & 1 & .227 \\
\hline Youth Age & & & & & & & & & & 1 \\
\hline
\end{tabular}

Note: $* p<0.05$

Note: $* * p<0.01$ 
Figure 1. Olson's Family Circumplex Model

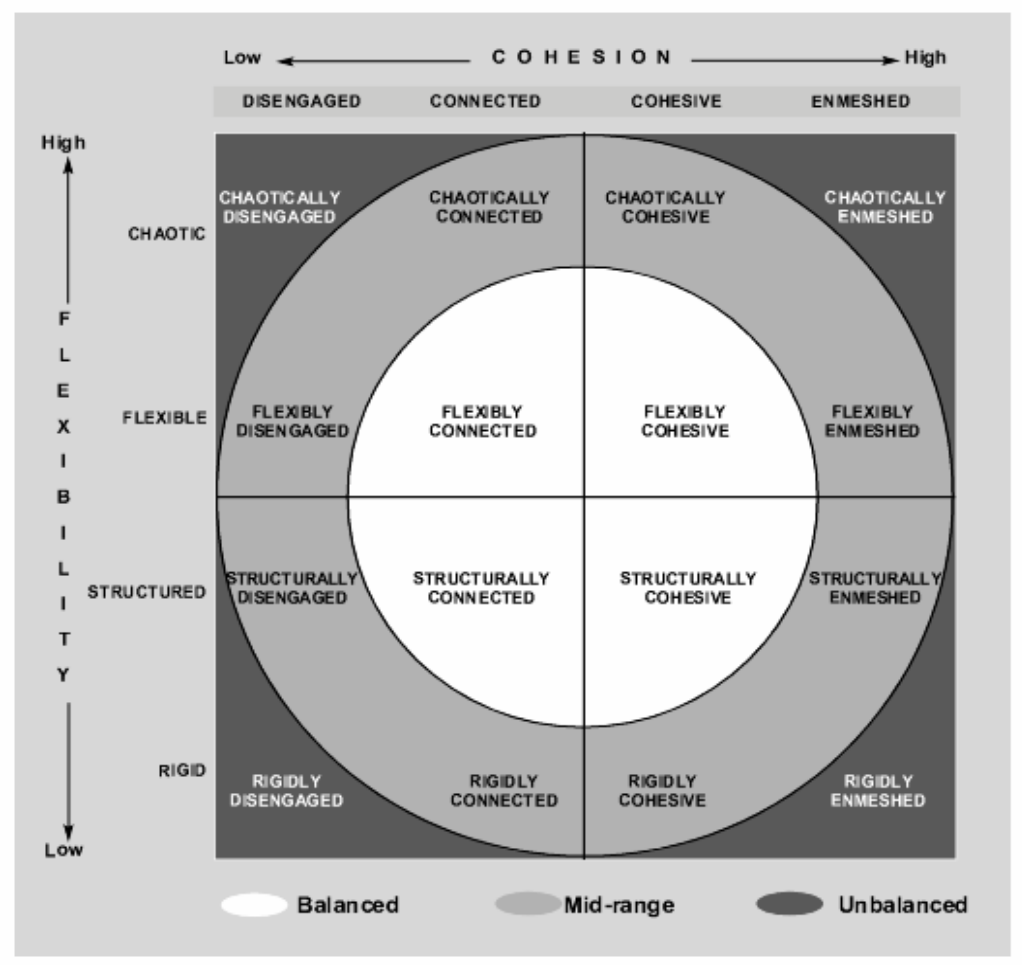


48 Leisure, Communication, and Family Functioning

Figure 2. Zabriskie's Core and Balance Model of Family Leisure Functioning

\section{Core and Balance Model of Family Leisure Functioning}

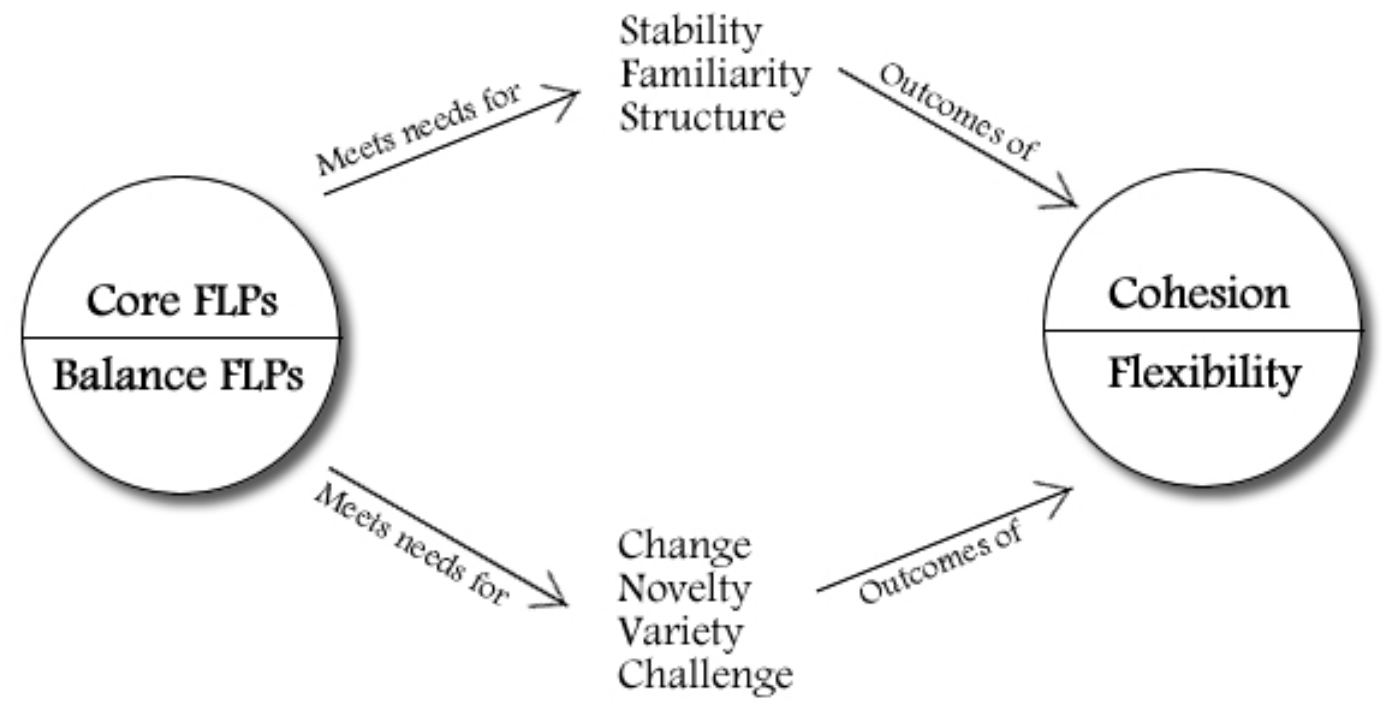


Figure 3. Youth Sample Paths

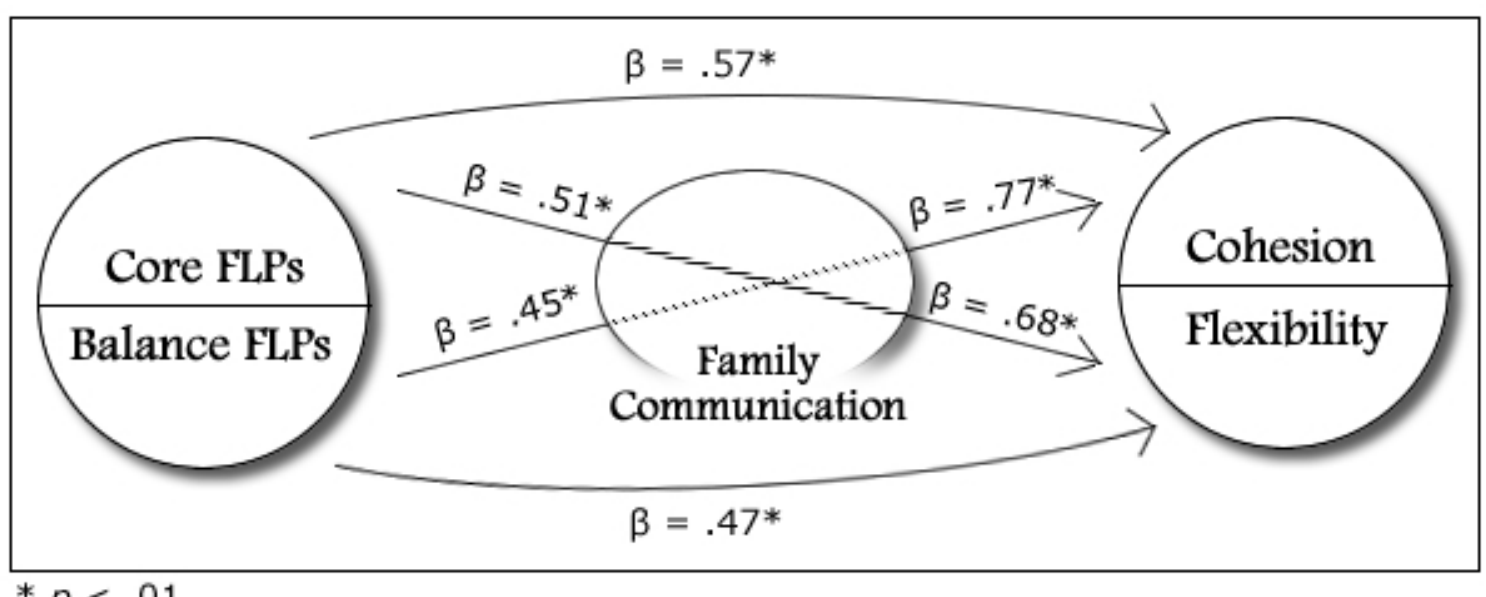

$* p<.01$ 
50 Leisure, Communication, and Family Functioning

Figure 4. Family Perspective Sample Paths

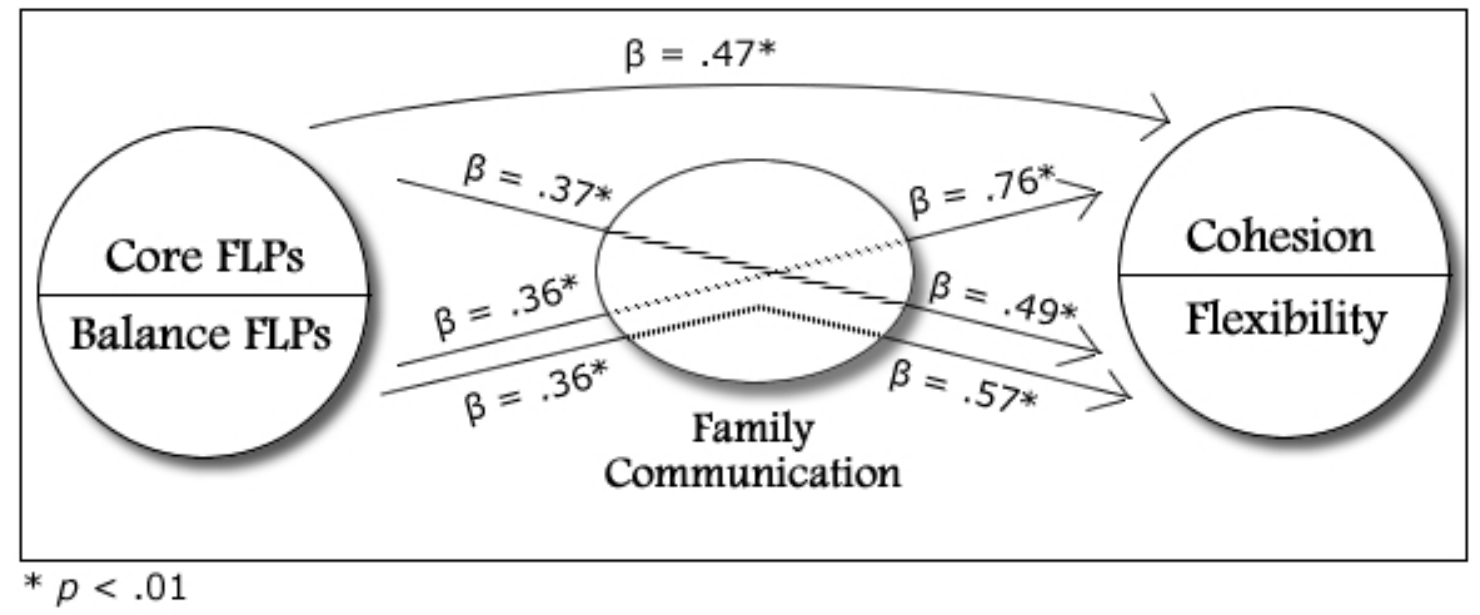


Figure 5. Revised Core and Balance Model of Family Leisure Functioning

\section{Core and Balance Model of Family Leisure Functioning}

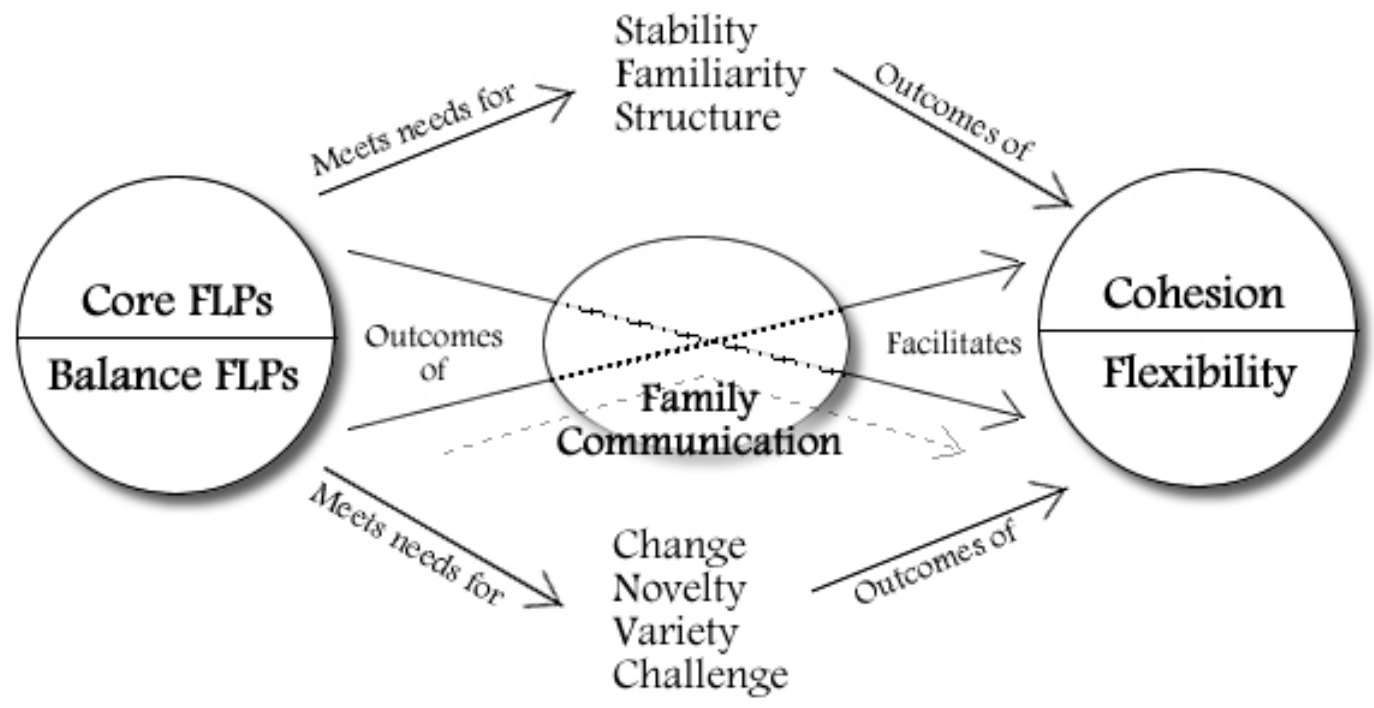


Appendix A

Prospectus 


\section{Chapter 1}

Introduction

The Circumplex Model of Marital and Family Functioning is based on family systems theory and determines family functioning derived from indicators of cohesion, flexibility, and communication (Olson, 2000). Cohesion is defined as togetherness, or the emotional bonding a family shares, and flexibility is the ability to cope with change. Olson defines communication (2000) in terms of a family's listening and speaking skills, self-disclosure, clarity, continuity tracking, and respect and regard. He posits that it helps in altering families cohesion and flexibility to meet developmental and situational demands that arise. A family who has good family communication will be better able to alter their cohesion and flexibility to meet developmental and situational demands that arise (Olson \& Gorall, 2003). Furthermore, family systems with poor communication tend to be unbalanced in regard to cohesion and flexibility, whereas family systems with good communication tend to be more balanced.

Zabriskie and McCormick (2001) developed the Core and Balance Model of Family Leisure Functioning, which is grounded in systems theory with particular focus on the Circumplex Model. Research using the Core and Balance Model has consistently found a positive relationship between family functioning and family leisure involvement (Christensen, 2004; Freeman \& Zabriskie, 2003; Smith, Taylor, Hill, \& Zabriskie, 2004; Zabriskie \& McCormick, 2001). These studies have determined that aspects of family functioning, cohesion and flexibility, were related differently to core and balance family leisure activity patterns. Core family leisure includes those activities that are usually 
frequent, home-based, and low in cost, while balance family leisure includes those activities that are novel, more challenging, and usually involve investment of time, effort, or cost.

The few studies that have examined the relationship between family leisure involvement and family communication have mostly focused on family adventure programs and their effect on family communication (Bandoroff \& Scherer, 1994; Huff, Widmer, McCoy, \& Hill, 2003; Kugath, 1997). There have been no studies, however, on general family leisure involvement and its relationship to family communication. There have also been no studies examining how communication interacts in the relationship between family leisure involvement and family functioning.

\section{Statement of the Problem}

The focus of this study is to investigate the relationship between family leisure involvement, family communication, and family functioning. More specifically, it is to see if family communication is a mediator of the relationship between family leisure involvement and family functioning.

Purpose of the Study

Since little is known about the role communication plays in the relationship between family leisure involvement and family functioning, this study will seek to investigate that role. These findings may help researchers gain a better understanding of the role family leisure involvement might play in developing good family functioning. 


\section{Significance of Study}

Systems theory is a paradigm that describes systems, or "sets of elements standing in interrelation among themselves and with the environment" (von Bertalanffy, 1975, p. 159). Theorists have used systems theory to describe the family (see Steinglass, 1987; Whitchurch \& Constantine, 1993). The family is a complex system composed of individuals interacting with one another. The Circumplex Model of Marital and Family Systems is based on family systems theory. The three dimensions addressed by the Circumplex Model are cohesion (defined as togetherness), flexibility (defined as the ability to cope with change), and communication. The combination of cohesion and flexibility is often used to indicate family functioning (see Olson \& Gorall, 2003). Cohesion in the family system is defined by Olson (2000) as "the emotional bonding that family members have toward one another" (p. 145). The focus of cohesion is how the members of the family systems balance their separateness versus their togetherness, or how they balance being alone versus being apart. Flexibility in the family system is defined by Olson (2000) as the "amount of change in its leadership, role relationships and relationship rules" (p. 147). Flexibility focuses on how family systems balance stability versus change, or how they adjust to changes in the family system. The movement of both flexibility and cohesion in a family to meet developmental and situational demands is facilitated by communication, the third dimension of the Circumplex Model (Olson \& Gorall, 2003).

Because a family relationship is intimate, misunderstandings in communication are likely to be more painful and have more serious consequences (Sieburg, 1985). In the 
Circumplex Model, communication facilitates the movement of family cohesion and family flexibility and enables a family to better alter their cohesion and flexibility to meet developmental and situation demands that arise (Olson \& Gorall, 2003). Olson (2000) measures couple and family communication by focusing on each system as a group, rather than on the individuals. He states that family systems with poor communication tend to be unbalanced in relation to their cohesion and flexibility, whereas family systems with good communication tend to be more balanced. Flexibility and cohesion have been used to measure family functioning's relationship to family leisure involvement.

Researchers have consistently found a positive relationship between family leisure patterns and indicators of family functioning (Hawks, 1991; Holman \& Epperson, 1984; Orthner \& Mancini, 1991). Recent literature has confirmed a positive relationship between family leisure involvement and family functioning and determined that cohesion and flexibility were related differently to core and balance family leisure patterns (Freeman \& Zabriskie, 2003; Smith, Taylor, Hill, \& Zabriskie, 2004; Zabriskie \& McCormick, 2001). The Core and Balance Model of Family Leisure Functioning addresses these two leisure patterns. Core is defined as family activities that are frequent, low in cost, and easily accessible. Balance activities are those family activities participated in less frequent, often include higher cost, and are novel. Core is typically related to the cohesion dimension of the Circumplex Model and balance is typically related to the flexibility dimension (Zabriskie \& McCormick, 2001).

There have been a few studies that have looked examined family communication in a leisure context (Bandoroff \& Scherer, 1994, Kugath, 1997; Huff et al. 2003). Leisure 
research has not, however, looked at the relationship between general family leisure involvement and family communication. Although leisure research has looked at the relationship between leisure and family functioning using the Core and Balance Model, the role communication plays in this relationship has not been examined. This study will seek to describe that role and discover if family communication is a mediator of the relationship between family leisure involvement and family functioning.

\section{Delimitations}

This study will be delimited in the following ways:

1. The sample will be parents of a family with at least one child who is 11 to 17 years of age and children from those families who are ages 11 to 17.

2. The three variables in this study will be family leisure involvement, family communication, and family functioning.

3. Family leisure involvement will be measured using the Family Leisure Activity Profile (FLAP) (Zabriskie \& McCormick, 2001). Cohesion, flexibility, and family functioning will be measured using the Family Flexibility and Cohesion Evaluation Scales (FACES II) (Olson, 2000). Family communication will be measured using the Family Communication Scale (FCS) (Olson, Gorall, \& Tiesel, 2004).

4. Parents from families with children between the ages of 12 to 17 and children from those families between at ages of 12 to 17 will complete the survey online.

5. Data collection will begin January 2005 , and will continue until a sufficient sample size has been collected. 


\section{Limitations}

This study will be limited in the following ways:

1. Because of financial and time constraints, a non-random sample will be used; therefore, findings cannot be generalized to the population at large.

2. Parental influence of child participation in the study cannot be monitored.

3. Causal relationships will not be determined by this study.

\section{Assumptions}

The study is based on the following assumptions:

1. Participants will answer the questionnaire honestly.

2. FACES II will give a valid and reliable representation of family functioning.

3. The FLAP will give a valid and reliable representation of family leisure involvement.

4. The FCS will give a valid and reliable representation of family communication.

\section{Hypotheses}

The study is designed to test the following null hypotheses:

$\mathrm{HO}_{1}$. There is no relationship between family leisure involvement and family functioning.

$\mathrm{HO}_{2}$. There is no relationship between family communication and family functioning.

$\mathrm{HO}_{3}$. There is no relationship between family leisure involvement and family communication.

$\mathrm{HO}_{4}$. Family communication is not a significant mediator of the relationship between family leisure involvement and family functioning. 


\section{Definition of Terms}

The following terms are defined to clarify their use in this study:

Balance leisure patterns. Balance family leisure patterns are depicted through family activities that are generally less common and less frequent than core activities and they provide novel experiences, usually requiring greater investment of resources (e.g., time, effort and money) and are usually not home based (Zabriskie \& McCormick, 2001).

Core leisure patterns. Core family leisure patterns are depicted in the common, everyday, low-cost, relatively accessible and often home-based family activities that many families do frequently (Zabriskie \& McCormick, 2001).

Family. A set or group of one or two parents with at least one child between the ages of 8 and 18 .

Family Cohesion. The emotional bonding that family members have toward one another (Olson, Bell, \& Portner, 1982).

Family Communication. A symbolic, transactional process, or the process of creating and sharing meanings (Galvin \& Brommel, 1982, p. 6).

Family Flexibility. The ability of a marital or family system to change its power structure, role relationships, and relationship rules in response to situational and developmental stress (Olson, Bell, \& Portner, 1982).

Family Functioning. Refers to the combination of the cohesion and flexibility of a family to meet developmental or situational demands (Olson \& Gorall, 2003). 
Family Leisure Involvement. Leisure involvement as defined by The Core and Balance Model of Family Leisure Functioning, using two general categories or patterns of family leisure: core and balance (Zabriskie \& McCormick, 2001). 


\section{Chapter 2}

\section{Literature Review}

The purpose of this study is to investigate the relationship between family leisure involvement, family communication, and family functioning; specifically the role family communication plays in the relationship between family leisure involvement and family functioning. This literature review will discuss (a) systems theory, (b) family systems theory, (c) the Circumplex Model, (d) family communication, (e) leisure and family functioning, and (f) summary.

Systems Theory

Systems theory is a paradigm that describes systems, or "sets of elements standing in interrelation among themselves and with the environment" (von Bertalanffy, 1975, p. 159). Three key assumptions found in systems theories are "that systems theories can unify science; that a system must be understood as a whole rather than in component parts; and that human systems are unique in their self-reflexivity" (Whitchurch \& Constantine, 1993, p. 328). Constantine (1986) defines a system as "a bounded set of interrelated elements exhibiting coherent behavior as a unit" (p. 50) and emphasizes the importance of not reducing the whole to solely examining its individual parts. $\mathrm{He}$ explains that the systems view is "characterized by its concern with wholes" and is "not reductionist. It does not attempt to explain wholes by reduction to simpler parts; rather, it understands parts by the functions they serve in the whole" (p. 49). Through psychiatry, GST entered family social science as families began to be viewed as systems and the foundations of family therapy were laid (Whitchurch \& Constantine, 1993). 
Family Systems Theory

The family is a complex system composed of individuals interacting with one another (Whitchurch \& Constantine, 1993). Rothbaum, Rosen, Ujiie, and Uchida (2002) posit that family systems theory is focused on family dynamics, which include structures, roles, communication patterns, boundaries, and power relations. Referring to Klein and White's (1996) work, Zabriskie and McCormick (2001) assert that family systems theory "holds that families are goal directed, self-correcting, dynamic, interconnected systems that both affect and are affected by their environment and by qualities within the family system itself”' (p. 281).

Like general systems theory, family systems theory views the whole of the family as greater than the sum of its parts. Fingerman and Bermann (2000) compare the family system to salt. The chemical composition of salt is a combination of sodium and chloride molecules. Upon contact with the end of the tongue, sodium, by itself, would explode while chloride would burn a hole through it. Yet together they form salt, which is not only harmless to the tongue, but is used to flavor food. While the members of a family are not necessarily volatile on their own, this comparison illustrates how the members of the family together are not just the sum of each member. Whitchurch and Constantine (1993) state that, "family processes can be understood as the product of the entire system, shifting the primary focus away from the individual family member to relationships among the members of the family system" (p. 330).

Whitchurch and Constantine (1993) claim that systems theories can be used in understanding intrafamily processes, through transactions among the family, when the 
family is defined as a system. These processes include family functioning, family conflict, family communication and transactional patterns, cohesion, separateness and connectedness among members, integration, and adaptation to change. The Circumplex Model of Marital and Family Systems is based on family systems theory.

Figure 1

Olson's Family Circumplex Model (D. H. Olson, personal communication, December 5, 2003)

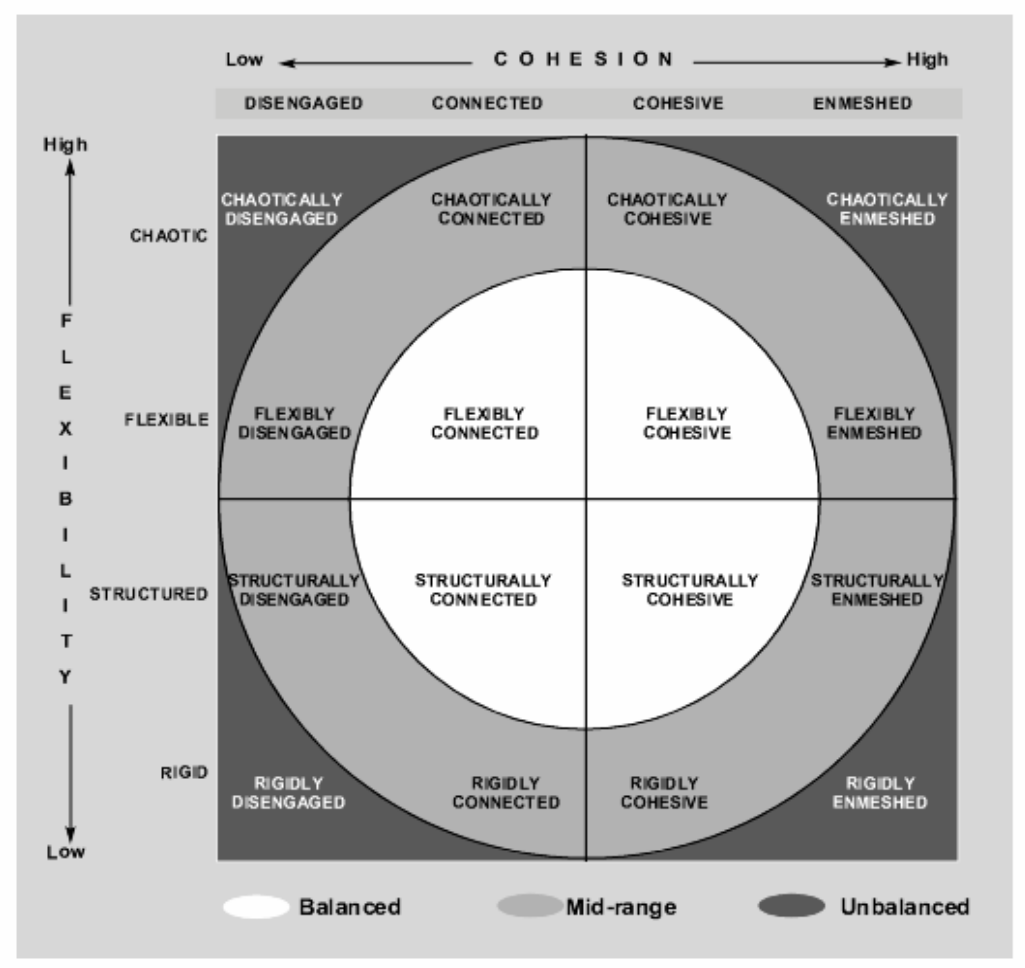

\section{Circumplex Model}

The Circumplex Model of Marital and Family Systems diagrams cohesion, flexibility, and communication within the family. Olson and DeFrain (2000) described the Family Circumplex Model as "a graphic representation of dynamic relationships 
within families" (p. 66). The model emphasizes how family members and their behaviors are interconnected (see Figure 1).

The three dimensions in the Circumplex Model are cohesion (defined as togetherness), flexibility (defined as the ability to cope with change), and communication (Olson \& Gorall, 2003). Communication is not shown graphically in Figure 1, but it facilitates movement in a family between the extremes of the other two dimensions. Therefore, "if a couple or a family has good communication skills, they are more likely to be close (cohesion dimension) and to be able to work out problems (flexibility dimension) when they arise" (Olson \& Gorall, 2003, p. 66). Cohesion and flexibility are often used as indicators of family functioning (see Olson \& Gorall, 2003).

Family Cohesion. Cohesion in the family system is defined by Olson (2000) as "the emotional bonding that family members have toward one another" (p. 145). Cohesion focuses on how the members of the family system balance their separateness versus their togetherness (Olson, 2000). Olson and Gorall (2003) compared a family’s separateness versus their togetherness to the two legs of a skier:

Professional skiers keep their legs together and smoothly shift between their legs and the edges of the skis, creating a balance on separateness and togetherness. Similarly, balanced couples and families are also able to shift between being apart and being connected in a fluid manner. Conversely, novice skiers tend to keep their legs too far apart (too much separateness) or too close together (enmeshed), thereby creating an unbalanced system. Unbalanced couples and families also tend to be stuck at either extreme of separateness or togetherness and are unable to find a balance (p. 523). 
Cohesion is separated into four different levels ranging from disengaged (very low cohesion), to separated (low to moderate), moving to connected (moderate to high), and ending at enmeshed (very high). Both disengaged and enmeshed levels of cohesion in a relationship are unbalanced and can lead to problems for the family relationship.

Relationships with separated and connected cohesion levels, however, have the ability to balance being alone versus being together in a more functional way (Olson, 2000).

Family Flexibility. Flexibility in the family system is defined by Olson (2000) as the "amount of change in its leadership, role relationships and relationship rules" (p. 147). Flexibility focuses on how family systems balance stability versus change (Olson, 2000). Olson and Gorall (2003) compared a family's balance of stability versus change to the body of a skier:

In watching professional skiers come down a ski slope, one sees fluidity in their movement left and right; they move their legs up and down to absorb the moguls while keeping the upper part of their body upright. In other words, there is both stability in the body and the ability to change. Likewise, in balanced couples and families, there is the ability not only to maintain stability but also to change, when necessarily. Conversely, novice skiers tend to keep their body rigid; then, when they hit a mogul, they become even more rigid (unbalanced), which often results in a chaotic fall. Unbalanced couples and families also seem to be either too focuses on stability (leading to rigidity) or too open to change (leading to chaos).

Flexibility has four levels that range from rigid (very low), to structured (low to moderate), moving to flexible (moderate to high), and ending at chaotic (very high). Both 
rigid and chaotic levels of flexibility are unbalanced and can also lead to problems for relationship development. Relationships with structured and flexible cohesion levels, however, have the ability to balance stability and change in a more functional way (Olson, 2000).

Families who balance cohesion, at the separated or connected level, and flexibility, at the structured or flexible level, will generally function better than unbalanced families. A family who is unbalanced will have an extreme level of cohesion, at the disengaged or enmeshed level, and an extreme level of flexibility, at the rigid or chaotic level (Olson, 2000). The use of cohesion and flexibility to indicate family functioning has been a common practice (see Bhushan \& Shirali, 1992; Kouneski, 2000; Olson \& Gorall, 2003).

Family Communication. Family communication acts as a process to make facts mutually manifest (Sperber \& Wilson, 1986) and develops and sustains reality in relationships (Berger \& Kellner, 1994). It is the third dimension in the Circumplex Model (Olson, 2000). Communication has been defined "as a symbolic, transactional process, or to put it more simply, as the process of creating and sharing meanings" (Galvin \& Brommel, 1982, p. 6). The symbols in communication can come through a variety of forms. They can be verbal behavior, or words, and nonverbal behavior such as facial expressions, eye contact, gesture, movement, body posture, appearance, and spatial distance (Galvin \& Brommel, 2003).

Communication is the facilitative dimension in the Circumplex Model and helps a family alter their cohesion and flexibility to meet developmental and situational demands 
that arise (Olson \& Gorall, 2003). Olson (2000) stated that family systems with poor communication tend to be unbalanced, whereas family systems with good communication tend to be more balanced. Olson and Gorall (2003) also compared a family's communication to skiing:

Professional skiers are very much 'in touch' with all aspects of the hill, including the moguls and type of snow conditions, and they use this feedback to make good decisions. Likewise, balanced couples and families are open to communication and feedback from other sources, so that they can better adjust their levels of cohesion and flexibility. Conversely, novice skiers are often unaware of the conditions of the hill or how to use that information. Lacking the feedback and information they need, they fail to improve their skiing. Unbalanced couples and families also ignore or are unable to accept feedback from others that could help them improve their ability to change their level of cohesion and flexibility (pp. 523-524).

Several studies support Olson's proposition that communication is a facilitator of family functioning (Anderson, 1986; Barnes \& Olson, 1985; Masselam, Marcus, \& Stunkard, 1990). Masselam et al. (1990) measured both family communication and family functioning with adolescents who had been unsuccessful in public school and were attending alternative schools, and compared them to the families with adolescents who were attending public school. They found that the adolescents in public school had higher levels of positive family communication and family functioning than did the adolescents in the alternative schools. This indicates that families who were balanced in 
terms of their cohesion and flexibility were more likely to have better family communication.

A study by Barnes and Olson (1985) also investigated the hypothesis that those families with balanced cohesion and flexibility would have better parent-adolescent communication. Their hypothesis was supported for the parents in their sample, but not for the children. When they combined the sample into a family perspective, they found that those families with good parent-adolescent communication were more likely to perceive their family balanced in cohesion and flexibility. Communication in the Circumplex model was also tested using instruments that were not developed by Olson in an effort to see if the model held true using instruments that were not created based purely on the Circumplex Model. Anderson's (1986) findings supported the Circumplex Model and found that positive communication skills were related to balanced cohesion and flexibility scores using different communication and family functioning instruments.

Austin and Nelson (1993) posited that the family communication environment was a primary way through which cultural beliefs and customs can be shared. According to Austin, Roberts, and Nass (1990), parents directly affected children's opinions about matters close to home. Direct parental influences also tended to be greater for issues that were concrete as opposed to abstract (Jennings \& Niemi, 1968, 1974; Sears, 1975). Because a family relationship is intimate, misunderstanding in communication is likely to be more painful and have more serious consequences (Sieburg, 1985).

Good family communication skills have been found to result in less serious forms of delinquency as well as lower rates of delinquency in adolescents (Clark \& Shields, 
1997), the development of conflict resolution (Koerner \& Fitzpatrick, 1997), children's resiliency to adverse environmental influences (Fitzpatrick \& Koerner, 1996), and the enactment of family rituals (Baxter \& Clark, 1996). Good family communication skills have also been found to mitigate the effects of television on children (Krcmar, 1998), and increase the positive adjustment of cancer patients (Gotcher, 1993). On the other hand, Poor family communication skills were found to result in a number of problems for individuals, including shyness (Huang, 1999), communication apprehension (Elwood \& Schrader, 1998; Hsu, 1998), unwillingness to communicate (Avtgis, 1999), the development of reticence (Kelly et al., 2002), and delinquent behavior in adolescents (Clark \& Shields, 1997).

The Parent-Adolescent Communication Scale (PAC) has been used frequently to measure communication within families. The PAC is made up of two scales that measure the degree of openness in family communication and the extent of problems in family communication (Barnes \& Olson, 1985). The open communication subscale in the PAC measures the positive aspects of a family's communication and the problem communication subscale in the PAC measures the negative aspects of a family's communication.

Many studies have used the PAC to measure the communication between adolescents and parents (Kouneski, 2000). Callahan, Cornell and Loyd (1990) found that the quality of parent-adolescent communication was consistently associated with perceived confidence in academic areas. Masselam et al. (1990) supported these findings 
in showing that adolescents attending alternative schools for struggling youth were less likely to have good family communication.

Among adolescent samples, good parent-adolescent communication was related to vigilant decision making (Brown \& Mann, 1990), high psychological health (Amerikaner, Monks, Wolfe, \& Thomas, 1994), lower indications of depression (Brage \& Meredith, 1994; Feldman, Rubenstein, \& Rubin, 1988), and emotional disclosure to parents (Papini, Farmer, Clark, Micka, \& Barnett, 1990). It also resulted in higher levels of satisfaction in remarried family households among the adolescents in the family (Henry \& Lovelace, 1995).

As effective as the PAC has been in measuring parent-adolescent communication, Olson et al. (2004) recognized the need for a scale that could be used in a wider variety of circumstances. They also had seen interest in a shorter scale. Therefore, Olson et al. (2004) have developed a new scale based on the Parent-Adolescent Communication Scale (PAC), the Family Communication Scale (FCS). It was released as part of the FACES IV (Olson et al., 2004).

Positive communication is believed to facilitate the movement between cohesion and flexibility within the Circumplex Model. Thus allowing families to function better in the face of various circumstances and change. Research has also shown that cohesion and flexibility are related to two different kinds of leisure patterns (Zabriskie \& McCormick, 2001). 


\section{Leisure and Family Functioning}

Researchers have consistently found a positive relationship between family recreation and indicators of family functioning (Hawkes, 1991; Holman \& Epperson, 1984; Orthner \& Mancini, 1991). Recent literature has looked specifically at the relationship between leisure and family functioning as defined by the balance between cohesion and flexibility (Christensen, 2004; Freeman \& Zabriskie, 2003; Smith et al., 2004; Zabriskie \& McCormick, 2001). The results of these studies have found a positive correlation between family leisure participation and family functioning. Furthermore, they found that aspects of family functioning were related differently to core and balance leisure patterns.

Core and Balance Model. The Core and Balance Model of Family Leisure Functioning is based on Kelly's (1999) concept of two types of leisure patterns and his argument that leisure is used to facilitate stability and change in the family system. Kelly defined the two kinds of leisure patterns as core and balance. Core activities are those that are easily accessible and low cost. They are the activities that are commonplace in a person's life. These activities might include playing a game of catch, playing board games, or preparing and eating dinner as a family. Balance activities, in contrast, suggest variety. They are activities that are novel and participated in less frequently. These activities might include family vacations, traveling, outdoor activities, or going to a cultural event. Iso-Ahola (1984), states that individuals seek structure and variety, stability and change, and familiarity and novelty in their leisure behavior. Zabriskie and 
McCormick (2001) contend that similar to individuals, families also seek to balance these needs through their leisure behavior.

Figure 2

Zabriskie’s Core and Balance Model of Family Leisure Functioning

\section{Core and Balance Model of Family Leisure Functioning}

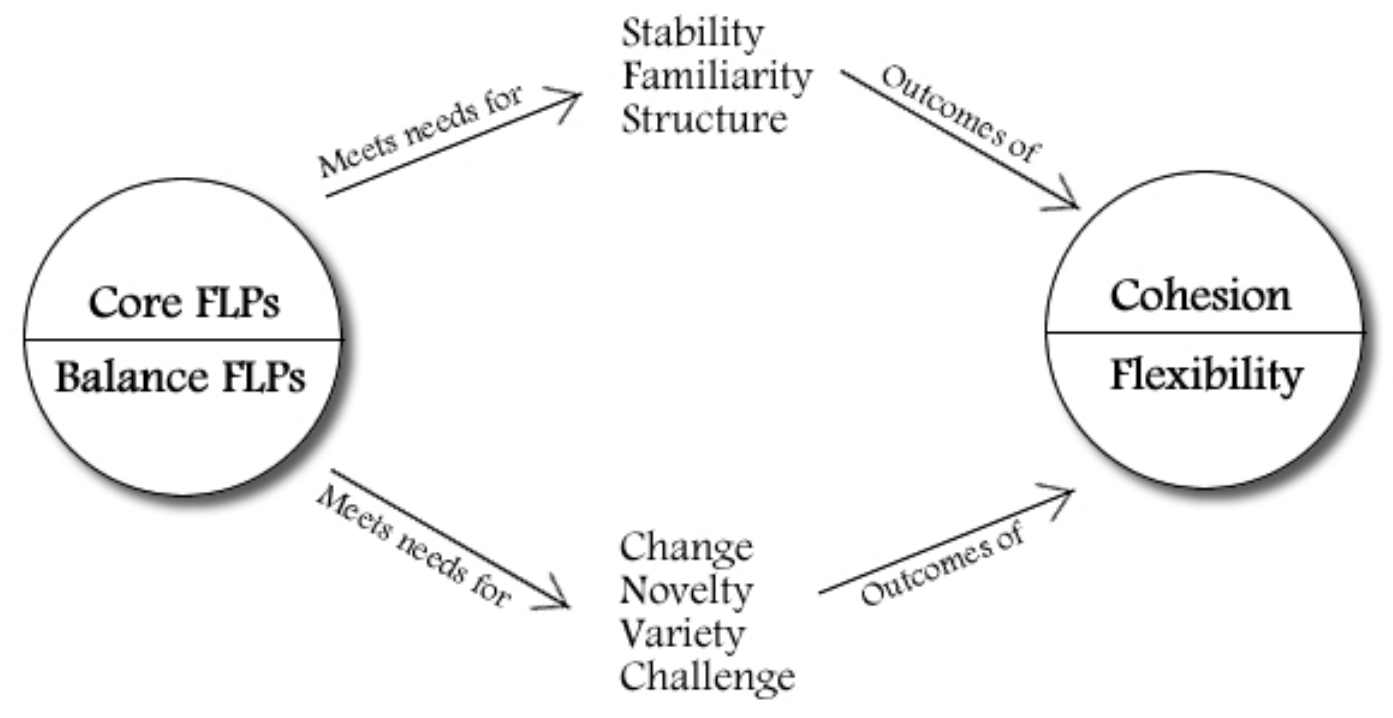

According to the model, core family leisure patterns address familiarity and stability in a family by regularly providing expected family leisure experiences that foster feelings of family closeness or cohesion. Conversely, balance family leisure patterns address novelty and change in a family by providing novel experiences that challenge families to negotiate and adapt to new input and to work together in a leisure context. Core activities, therefore, are related to the cohesion dimension of the Circumplex Model and balance activities are related to the flexibility dimension (see Figure 2) (Zabriskie \& McCormick, 2003). 
Zabriskie and McCormick (2001) conducted the preliminary test of the Core and Balance Model of Family Leisure Functioning. Their sample consisted of 138 students from three lower-division undergraduate health education courses at a large midwestern university. Overall, their findings indicated a significant relationship between family leisure variables and aspects of family functioning. They also found that core leisure activities was a stronger predictor of family cohesion than balance, while core and balance were almost equally strong predictors of family flexibility.

Further studies have used the Core and Balance Model to investigate the relationship between family leisure involvement and family functioning (Christensen, 2004; Freeman \& Zabriskie, 2003; Smith et al., 2004). Freeman and Zabriskie (2003) tested intact families $(n=197)$ who had adopted children of color. They found a positive relationship between family leisure involvement and family functioning. Core and balance were significant predictors of family functioning for the parents in their sample, while only core was a significant predictor of family functioning for the children.

Smith et al. (2004) conducted a pilot study looking at 46 college students who had lived in a single-parent family the two years prior to graduation from high school. Core and balance were both significant predictors of family flexibility, while core was the only significant predictor of family cohesion. Their findings also showed that core and balance activities were related differently to cohesion and flexibility, confirming the results of the previous studies.

Communication in Leisure Research. Although the relationship between family functioning and family leisure patterns has been investigated, little research has been 
conducted investigating family communication, the third dimension of the Circumplex Model, and leisure. Several individuals have hypothesized that outdoor recreation will improve family communication (Gass, 1993; Orthner et al. 1994). This hypothesis has been supported by a few studies focused on family adventure programs (Bandoroff \& Scherer, 1994, Kugath, 1997; Huff et al. 2003).

Banderoff and Scherer (1994) found that families with problem adolescents who participated in a 21-day survival program reported improved communication within the family. Kugath (1997) discovered that fathers in families, who participated in an eighthour intensive family adventure program including rock climbing and white water rafting, had significant increases in their perceptions of family communication. Similarly, families in Huff et al. (2003) study improved their level of parent-adolescent communication after a challenging family outdoor recreation experience. The role of family communication in the relationship between family leisure involvement and family functioning, however, has not been investigated.

Summary

Family Systems Theory uses the tenants of General Systems Theory to look at the family as a system, or as a whole (Whitchurch \& Constantine, 1993). The Circumplex Model of Marital and Family Systems is based on Family Systems Theory. The Circumplex Model addresses cohesion, flexibility, and communication within the family system. When family cohesion and flexibility are balanced the family will be more likely to function well. Communication is a dimension of the Circumplex Model that facilitates the movement of cohesion and flexibility (Olson, 2000). Leisure researchers have 
investigated leisure involvement and family functioning (Freeman \& Zabriskie, 2003; Zabriskie \& McCormick, 2001) as well as family adventure programs and family communication (Bandoroff \& Scherer, 1994, Kugath, 1997; Huff et al. 2003). Leisure researchers have not, however, investigated the role family communication plays in the relationship between family leisure and family functioning. Therefore, the purpose of this study is to investigate the relationship between family leisure involvement, family communication, and family functioning. More specifically, it is to ascertain if family communication is a mediator of the relationship between family leisure involvement and family functioning. 


\section{Chapter 3}

\section{Methods}

The purpose of this study is to investigate the relationship between family leisure involvement, family communication, and family functioning; specifically the role family communication plays in the relationship between family leisure involvement and family functioning. This study will be conducted using the following steps: (a) selection of subjects, (b) selection of test instruments, (c) data collection procedures, and (d) treatment of data.

Selection of Subjects

Study participants be recruited using a referral sample. Participants will be given a link to the research instrument and will be asked to refer their friends to the site. The sample will consist of parents of children ages 12 to 17 and children from those families who are living at home and are between the ages of 12 and 17 . These ages for the children were selected because Olson et al. (1982) suggests that children should be at least 12 years of age to use the FACES II instrument.

Both parents and children from the same family will be sought to gain a better understanding of the family system as a whole rather than one individual from the family system. A sample size of 200 families will be sought.

\section{Selection of Test Instruments}

Three instruments will be used for this study: the Family Flexibility and Cohesion Evaluation Scales (FACES II) (Olson et al., 1982), the Family Communication Scale 
(FCS) (Olson et al., 2004), and the Family Leisure Activity Profile (FLAP) (Zabriskie \& McCormick, 2001). Demographic questions will also be asked.

FACES II is an instrument based on the Family System Circumplex Model (Olson, 2000). It includes two scales, with 16 cohesion items and 14 flexibility items, for a total of 30 times. The 16 cohesion items include eight concepts, with two items for each concept, related to the cohesion dimensions of emotional bonding, family boundaries, coalitions, time space, friends, decision-making, and interests and recreation. The 14 flexibility items include six concepts, with two or three items for each concept, related to the flexibility dimensions of assertiveness, leadership, disciple, negotiations, roles and rules (Olson et al., 1982).

The FACES II questions measured on a five-point Likert scale, with one indicating "almost never" and five "almost always". A total score for both cohesion and flexibility is computed by summing the values for each (some items are reverse scored). Both scores are compared to a sliding scale that determines the "type" of cohesion and flexibility the family has. These types are scored from one to eight for each, with one equaling "disengaged" for cohesion and "rigid" for flexibility and eight equaling "very connected" for cohesion and "very flexible" for flexibility. Adding the type scores of both cohesion and flexibility and dividing by two gives the family functioning score for the family. Olson et al. (1992) reported acceptable levels of internal consistency for two national samples $(\alpha=.88$ and $\alpha=.86$ for cohesion and $\alpha=.78$ and $\alpha=.79$ for flexibility). 
Olson et al (2004) developed the Family Communication Scale (FCS) as a short and reliable scale to measure communication within the family. It is based on the ParentAdolescent Communication Scale (Barnes \& Olson, 1985) and was developed because there was interest in a shorter scale that was more generic. It consists of 10 questions. The 10 items are measured on a five-point Likert scale, with one describing the family "not at all" and five describing the family "very well". The total score indicates how functional the family communication is within the family. Olson et al. (2004) reported an acceptable level of internal consistency in a national sample for the scale $(\alpha=.88)$.

The Family Leisure Activity Profile (FLAP) identifies and measures two types of family leisure patterns, core and balance. The FLAP includes 16 questions. Eight of the questions are representative of core family leisure activities, and eight questions are representative of balance family leisure patterns. For each type of activity respondents indicate if they do the activity, and if so indicate the frequency and duration of participation. They then indicate how satisfied they are on a five-point Likert scale with one equaling "very dissatisfied" and five "very satisfied". Multiplying frequency by duration give an index score for each question. The index scores for questions 1-8 are summed to calculate a core index score and question 9-16 are summed for a balance index score. Summing the core and balance index scores creates a total family leisure index score. Significant $(\mathrm{p}<.01)$ test-retest correlations were reported for core $(r=.74)$ and balance $(r=.78)$ family leisure indices with a five-week period between administrations in a college student sample. An international panel of experts $(n=8)$ 
confirmed evidence of content validity of the core and balance categories based on the theoretical model (Zabriskie \& McCormick, 2001).

Demographic questions include age, gender, ethnicity, religion, and marital status. There will also be questions about their family size and composition (i.e. number of children, children's ages, etc.)

\section{Data Collection Procedures}

Data will be collected using an online survey that will include all of the test instruments, from January 2005 until a sufficient sample size is collected. The study participants will be given the URL of the survey and asked to complete it on their own time. On the online survey's first page, participants will read a paragraph informing them that participation in the study is voluntary and that they are allowed to stop at any time. It will also state that completing the questionnaire implies consent to participate in the study. As there will be no identifying questions on the survey, this will ensure confidentiality of the subjects. Participants' responses will be stored on a database and downloaded into an Excel spread sheet for data analysis. Access to the data will be password protected, guaranteeing the security of the data.

\section{Treatment of Data}

The data will first be cleaned to check for input errors. An index score will be calculated for core and balance activities from the FLAP. Cohesion and flexibility scores will be calculated from FACES II. A family communication score will be calculated from the FCS. Zero-order correlations will be calculated between the test variables to look for significant relationships and check for multicollinearity. Multiple regression analyses will 
be calculated using all significant independent variables on the dependent variable to determine which independent variables predict change in the dependent variable. Should both family leisure involvement and family communication be significant predictors of family functioning, a path analysis will be performed to determine if family communication is a mediator of the relationship between family leisure involvement and family functioning. 


\section{References}

Amerikaner, M., Monks, G., Wolfe, P., \& Thomas, S. (1994). Family interaction and individual psychological health. Journal of Counseling \& Development, 72, 614620.

Anderson, S. A. (1986). Cohesion, flexibility, and communication: A test of an Olson circumplex model. Family Relations, 35, 289-293.

Austin, E. W., \& Nelson, C. L. (1993). Influences of ethnicity, family communication and media on adolescents' socialization to U.S. politics. Journal of Broadcasting \& Electronic Media, 37(4), 419-436.

Austin, E. W., Roberts, D. F., \& Nass, C. I. (1990). Influences of family communication on children's television interpretation processes. Communication Research, 17, $545-564$.

Avtgis, T. A. (2000). The relationship between unwillingness to communicate and family communication patterns. Communication Research Reports, 16, 333-338.

Bandoroff, S., \& Scherer, D. G. (1994). Wilderness family therapy: An innovative treatment approach for problem youth. Journal of Child and Family Studies, 3(2), 175-191.

Barnes, H. L., \& Olson, D. H. (1985). Parent-adolescent communication and the circumplex model. Child Development, 56, 438-447.

Baxter, L. A., \& Clark, C. L. (1996). Perceptions of family communication patterns and the enactment of family rituals. Western Journal of Communication, 60, 254-268. 
Berger, P., \& Kellner, H. (1994). Marriage and the construction of reality: An exercise in the microsociology of knowledge. In G. Handel \& G. G. Whitchurch (Eds.), The psychosocial interior of the family (4th ed.; pp. 19-36). New York: Aldine De Gruyter.

Bhushan, R., \& Shirali, K. A. (1992). Family types and communication with parents: A comparison of youth at different identity levels. Journal of Youth and Adolescence, 21(6), 687-697.

Brage, D. \& Meredith, W. (1994). A causal model of adolescent depression. The Journal of Psychology, 128(4), 455-468.

Brown, J. E., \& Mann, L. (1990). The relationship between family structure and process variables and adolescent decision making. Journal of Adolescence, 13, 25-37.

Callahan, C. M., Cornell, D. G., \& Loyd, B. (1990). Perceived competence and parentadolescent communication in high ability adolescent females. Journal for the Education of the Gifted, 13(3), 256-269.

Christensen, O. D. (2004). An examination of perceptions for family acculturation, family leisure involvement, and family functioning among Mexican-Americans. Unpublished master's thesis, Brigham Young University, Provo, Utah.

Clark, R. D., \& Shields, G. (1997). Family communication and delinquency. Adolescence, 32, 81-93.

Constantine, L. L. (1986). Systems in general: Basic general systems theory. In L. L. Constantine (ed.), Family paradigms: The practice of theory in family therapy (pp. 45-67). New York: Guilford. 
Elwood, T. D., \& Schrader, D. C. (1998). Family communication patterns and communication apprehension. Journal of Social Behavior \& Personality, 13, 493502.

Feldman, S. S., Rubenstein, J. L., \& Rubin, C. (1988). Depressive affect and restraint in early adolescents: Relationships with family structure, family process and friendship support. Journal of Early Adolescence, 8(3), 279-296.

Fingerman, K. L., \& Bermann, E. (2000). Applications of family systems theory to the study of adulthood. International Journal of Aging and Human Development, 51(1), 5-29.

Fitzpatrick, M. A., \& Koerner, A. F. (1996). Family communication schemata and social functions of communication. Paper presented at the International Research Colloquium on Communication Research, Moscow, Russia.

Freeman, P., \& Zabriskie, R. B. (2003). Leisure and family functioning in adoptive families: Implications for therapeutic recreation. Therapeutic Recreation Journal, 37(1), 73-93.

Galvin, K. M., \& Brommel, B. J. (1982). Family communication: Cohesion and change. Glenview, IL: Scott, Foresman and Company.

Gass, M. A. (1993). Adventure therapy: Therapeutic applications of adventure programming. Dubuque, IA: Dendall/Hunt Publishing Company.

Gotcher, J. M. (1993). The effects of family communication on psychosocial adjustment of cancer patients. Journal of Applied Communication Research, 21(2), 176-188. 
Hawks, S. R. (1991). Recreation in the family. In S. J. Bahr (Ed.), Family research: A sixty year review, 1930-1990 (pp. 387-433). New York: Lexington Books.

Henry, C. S., \& Lovelace, S. G. (1995). Family resources and adolescent family life satisfaction in remarried family households. Journal of Family Issues, 16(6), 765 786.

Holman, T. B., \& Epperson, A. (1984). Family and leisure: A review of the literature with research recommendations. Journal of Leisure Research, 16, 277-294.

Hsu, C. F. (1998). Relationships between family characteristics and communication apprehension. Communication Research Reports, 15, 91-98.

Huang, L. N. (1999). Family communication patterns and personality characteristics. Communication Quarterly, 47, 230-243.

Huff, C., Widmer, M., McCoy, K., \& Hill, B. (2003). The influence of challenging outdoor recreation on parent-adolescent communication. Therapeutic Recreation Journal, 37(1), 18-37.

Iso-Ahola, S. E. (1984). Social psychological foundations of leisure and resultant implications for leisure counseling. In E. T. Dowd (Ed.), Leisure counseling: Concepts and applications (pp. 97-125). Springfield, IL: Charles C. Thomas.

Jennings, M. K., \& Niemi, R. G. (1968). The transmission of political values from parent to child. American Political Science Review, 62, 169-184.

Jennings, M. K., \& Niemi, R. G. (1974). The political character of adolescence. Princeton: Princeton University Press. 
Kelly, J. R. (1999). Leisure behaviors and styles: Social, economic, and cultural factors. In E. L. Jackson \& T. L. Burton (Eds.), Leisure Studies: Prospects for the TwentyFirst Century (pp. 135-150). State College, PA: Venture.

Kelly, L., Keaten, J. A., Finch, C., Duarte, I. B., Hoffman, P., \& Michels, M. M. (2002). Family communication patterns and the development of reticence. Communication Education, 51(2), 202-209.

Klein, D. M., \& White, J. M. (1996). Family theories: An introduction. Thousand Oaks, CA: Sage.

Koerner, A. F., \& Fitzpatrick, M. A. (1997). Family type and conflict: The impact of conversation orientation and conformity orientation on conflict in the family. Communication Studies, 48, 59-78.

Koerner, A. F., \& Fitzpatrick, M. A. (2002). Toward a theory of family communication. Communication Theory, 12(1), 70-91.

Kouneski, E. F. (2000). Family assessment and the circumplex model: New research developments and applications. Unpublished paper. St. Paul, MN: Family Social Science, University of Minnesota.

Krcmar, M. (1998). The contribution of family communication patterns to children interpretations of television violence. Journal of Broadcasting \& Electronic Media, 42(2), 250-265.

Kugath, S. (1997). The effects of family participation in outdoor adventure programs. Unpublished doctoral dissertation, Indiana University, Indiana. 
Masselam, V. S., Marcus, R. F., \& Stunkard, C. L. (1990). Parent-adolescent communication, family functioning, and school performance. Family Therapy, 27(2), 177-189.

Olson, D. H. (2000). Circumplex Model of Marital and Family Systems. Journal of Family Therapy, 22(2), 144-167.

Olson, D. H., \& DeFrain, J. (2000). Marriage and the family: Diversity and strengths, (pp. 66-97). Mountain View, CA: Mayfield.

Olson, D. H., Portner, J., and Bell, R. (1982). FACES II: Family adaptability and cohesion evaluation scales. St. Paul, MN: Family Social Science, University of Minnesota.

Olson, D. H., \& Gorall, D. M. (2003). Circumplex model of marital and family systems. In F. Walsh (Ed.) Normal Family Processes 3rd ed, (pp. 514-547). New York: Guilford.

Olson, D. H., Gorall, D. M., \& Tiesel, J. W. (2004). Faces IV Package. Minneapolis, MN: Life Innovations.

Orthner, D. K., Barnett-Morris, L., \& Mancini, J. A. (1994). Leisure and family over the life cycle. Handbook of Developmental Family Psychology \& Psychopathology, (pp. 176-201), New York: John Wiley \& Sons.

Orthner, D. K., \& Mancini, J. A. (1991). Benefits of leisure for family bonding. In B. L. Driver, P. J. Brown, \& G. L. Peterson (Eds.), Benefits of leisure (pp. 215-301). State College, PA: Venture. 
Papini, D. R., Farmer, F. F., Clark, S. M., Micka, J. C., \& Barnett, J. K. (1990). Early adolescent age and gender differences in patterns of emotional self-disclosure to parents and friends. Adolescence, 25, 959-976.

Rothbaum, F., Rosen, K., Ujiie, T., \& Uchida, N. (2002). Family systems theory, attachment theory, and culture. Family Process, 41, 328-350.

Sears, D. O. (1975). Political socialization. In F. I. Greenstein \& N. W. Polsby (Eds.), Handbook of political science: Vol. 2. Micropolitical theory (pp. 93-153). Reading, MA: Addison-Wesley.

Sieburg, E. (1985). Family communication: An integrated systems approach. New York: Gardner Press.

Smith, K. M., Taylor, S., Hill, B., \& Zabriskie, R. B. (2004). Family functioning and leisure in single-parent families. Abstracts from the 2004 Leisure Research Symposium. Ashburn, VA: National Recreation and Parks Association.

Sperber, D., \& Wilson, D. (1986). Relevance: Communication and cognition. Cambridge, MA: Harvard University Press.

Steinglass, P. (1987). A systems view of family interaction in psychopathology. In T. Jacob (Ed.), Family Interaction and Psychopathology (pp. 25-65). New York: Plenum Press.

Tulloch, A. L., Blizzard, L., \& Pinkus, Z. (1997). Adolescent-parent communication in self-harm. Journal of Adolescent Health, 21(4), 267-276.

von Bertalanffy, L. (1950). An outline of general systems theory. British Journal for the Philosophy of Science, 1, 134-165. 
von Bertalanffy, L. (1975). Perspectives on general systems theory: Scientificphilosophical studies. New York: George Braziller.

Wells, M. S., Widmer, M. A., \& McCoy, J. K. (2004). Grubs and Grasshoppers: The influence of challenging recreation on the collective efficacy of families with atrisk youth. Family Relations 53( 3), 326-333.

Whitchurch, G. G., \& Constantine, L. L. (1993). Systems theory. In P. G. Boss, W. J. Doherty, R. LaRossa, W. R. Schumm, \& S. K. Steinmetz (Eds.), Sourcebook of Family Theories and Methods: A Contextual Approach (pp. 325-349). New York: Plenum Press.

Zabriskie, R. B. (2000). An examination of family and leisure behavior among families with middle school aged children. Unpublished doctoral dissertation, Indiana University, Bloomington, Indiana.

Zabriskie, R. B., \& McCormick, B. P. (2001). The influences of family leisure patterns on perceptions of family functioning. Family Relations, 50, 281-289.

Zabriskie, R. B., \& McCormick, B. P. (2003). Parent and child perspectives of family leisure involvement and satisfaction with family life. Journal of Leisure Research, 35(2), 163-189. 
Appendix A-1a

Informed Consent 
Surveys page

\section{Consent to be a Research Subject}

This research study is being conducted by K. M. Smith at Brigham Young University to determine what role family communication plays in family leisure involvement and family functioning. This questionnaire contains 16 question about family leisure involvement, 30 questions about family functioning, 10 questions about family communication, 12 questions about religiosity, and 10 demographic questions. It should take approximately 15 minutes to complete. There are minimal risks for participation in this study. However, you may feel emotional discomfort when answering questions about your family. There are no direct benefits for participation in this study. It is hoped, however, that the knowledge gained from this study will help researchers better understand the benefits derived from family leisure involvement and what role communication plays in those benefits. All information will remain completely confidential and will only be reported in general numbers with no identifying information. All data will be stored on a password-protected computer. Only the researcher will have access to the data. After the research is completed, the data will be erased. There is no compensation for participation in this study. Participation is voluntary. You have the right to withdraw or refuse to participate at any time. If you have questions regarding this study, you may contact K. M. Smith at 422-3215, kevins@byu.edu. If you have questions you do not feel comfortable asking the researcher, you may contact Dr. Renea Beckstrand, IRB Chair, 422-3873, renea_beckstrand@byu.edu. Completion of this online survey is regarded as implied consent to participate in this research.

The links below go to the two surveys. If you are a parent, please click on the Parent link. If you are the child (11 - 17 years of age) of a participating parent, please click on the Youth link. If possible, please have both a parent and a child from the same family fill out a survey, though it is not necessary for participation. Thank you!

\section{$\underline{\text { Parent }}$}

$\underline{\text { Youth }}$

Survey conducted by the Recreation Management Youth Leadership department at Brigham Young University.
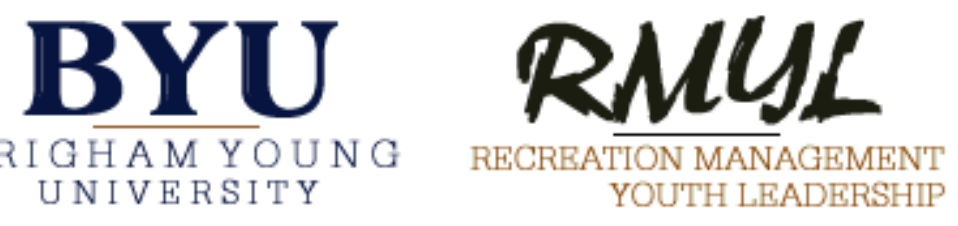
Appendix A-1b

Family Leisure Activity Profile 
(**The youth questionnaire will contain all of this except for the demographic section.

They will only be asked for their age and gender**)

\section{Family Leisure Activity Profile}

The following questions ask about the activities you do with family members. Please refer to the last year or so. These questions ask about groups of activities, so try to answer in terms of the group as opposed to any one specific example. This may require you to "average" over a few different activities. Don't worry about getting it exactly "right." Just give your best estimate.

1. Do you have meals, at home, with family members?

YES

$\mathrm{NO}$

\begin{tabular}{|l|l|}
\hline \multicolumn{2}{|c|}{ If YES how often? } \\
\hline At least daily & \\
\hline At least weekly & \\
\hline At least monthly & \\
\hline At least annually & \\
\hline
\end{tabular}

\begin{tabular}{|r|r|r|r|r|}
\hline \multicolumn{5}{|c|}{ For about how long per time? (check only one) } \\
\hline$<1$ hour & $1-2$ hrs & $2-3$ hours & \\
\hline $3-4$ hours & & $4-5$ hours & & $5-6$ hours \\
\hline
\end{tabular}

How satisfied are you with your participation with family members in these activities?

$$
\text { (please circle one) }
$$

Very

Dissatisfied

1
2
Very

Satisfied 
2. Do you participate in home-based activities (for example watching TV/videos, listening to music, reading books, singing, etc.) with family members?

YES _ $\quad \mathrm{NO}$

\begin{tabular}{|c|c|c|c|}
\hline If YES how often? & \multicolumn{3}{|c|}{ For about how long per time? (check only one) } \\
\hline At least daily & $<1$ hour & $1-2 \mathrm{hrs}$ & $2-3$ hours \\
\hline At least weekly & 3-4 hours & 4-5 hours & 5-6hours \\
\hline At least monthly & 6-7 hours & $7-8$ hours & 8-9 hours \\
\hline At least annually & 9-10 hours & $>10$ hours & $>1$ day \\
\hline
\end{tabular}

How satisfied are you with your participation with family members in these activities?

(please circle one)

Very

Dissatisfied

1
2
Very

Satisfied

4

5

3. Do you participate in games (for example playing cards, board games, video games, darts, billiards, etc.) with family members?
YES
$\mathrm{NO}$

\begin{tabular}{|c|c|}
\hline \multicolumn{2}{|l|}{ If YES how often? } \\
\hline At least daily & \\
\hline At least weekly & \\
\hline At least monthly & \\
\hline At least annually & \\
\hline
\end{tabular}

\begin{tabular}{|c|c|c|}
\hline \multicolumn{3}{|c|}{ For about how long per time? (check only one) } \\
\hline$<1$ hour & $1-2 \mathrm{hrs}$ & 2-3 hours \\
\hline 3-4 hours & $4-5$ hours & 5-6hours \\
\hline 6-7 hours & $7-8$ hours & 8-9 hours \\
\hline $9-10$ hours & $>10$ hours & $>1$ day \\
\hline
\end{tabular}

How satisfied are you with your participation with family members in these activities?

$$
\text { (please circle one) }
$$

Very

Dissatisfied

1
2
3
Very

Satisfied

4

5 
4. Do you participate in crafts, cooking, and/or hobbies (for example drawing, scrap books, baking cookies, sewing, painting, ceramics, etc.) with family members?

YES _ N NO

\begin{tabular}{|l|l|}
\hline \multicolumn{2}{|c|}{ If YES how often? } \\
\hline At least daily & \\
\hline At least weekly & \\
\hline At least monthly & \\
\hline At least annually & \\
\hline
\end{tabular}$\quad$\begin{tabular}{|r|r|r|r|r|r|}
\hline \multicolumn{5}{|c|}{ For about how long per time? (check only one) } \\
\hline$<1$ hour & & $1-2$ hrs & $2-3$ hours & \\
\hline $3-4$ hours & & $4-5$ hours & & $5-6$ hours & \\
\hline $6-7$ hours & & $7-8$ hours & & $8-9$ hours & \\
\hline $9-10$ hours & & $>10$ hours & & $>1$ day & \\
\hline
\end{tabular}

How satisfied are you with your participation with family members in these activities?

(please circle one)

Very

Dissatisfied

1

3

4

Very

Satisfied

5

5. Do you participate in home-based outdoor activities (for example star gazing, gardening, yard work, playing with pets, walks, etc.) with family members?

YES _ N NO

\begin{tabular}{|c|c|c|c|}
\hline If YES how oft & \multicolumn{3}{|c|}{ For about how long per time? (check only one) } \\
\hline At least daily & $<1$ hour & $1-2 \mathrm{hrs}$ & 2-3 hours \\
\hline At least weekly & 3-4 hours & 4-5 hours & 5-6hours \\
\hline At least monthly & 6-7 hours & $7-8$ hours & 8-9 hours \\
\hline At least annually & 9-10 hours & $>10$ hours & $>1$ day \\
\hline
\end{tabular}

How satisfied are you with your participation with family members in these activities?

(please circle one)

Very

Dissatisfied

1
2
Very

Satisfied

4
5 
6. Do you participate in home-based sport/games activities (for example playing catch, shooting baskets, frisbee, bike rides, fitness activities, etc.) with family members?

$$
\text { YES _ } \quad \mathrm{NO}
$$

\begin{tabular}{|l|l|r|r|r|r|r|}
\hline \multicolumn{1}{|c|}{ If YES how often? } \\
\hline At least daily & \\
\hline At least weekly & \multicolumn{5}{|c|}{ For about how long per time? (check only one) } \\
\hline At least monthly & $<1$ hour & & $1-2$ hrs & $2-3$ hours & \\
\hline At least annually & \\
\hline
\end{tabular}

How satisfied are you with your participation with family members in these activities?

(please circle one)

Very

Dissatisfied

1
2
Very

Satisfied

4

5

7. Do you attend other family members' activities (for example watching or leading their sporting events, musical performances, scouts, etc.)?

$$
\text { YES _ } \quad \mathrm{NO}
$$

\begin{tabular}{|c|c|c|c|}
\hline If YES how often & \multicolumn{3}{|c|}{ For about how long per time? (check only one) } \\
\hline At least daily & $<1$ hour & $1-2 \mathrm{hrs}$ & 2-3 hours \\
\hline At least weekly & 3-4 hours & 4-5 hours & 5-6hours \\
\hline At least monthly & 6-7 hours & $7-8$ hours & 8-9 hours \\
\hline At least annually & 9-10 hours & $>10$ hours & $>1$ day \\
\hline
\end{tabular}

How satisfied are you with your participation with family members in these activities?

$$
\text { (please circle one) }
$$

Very

Dissatisfied

1
2
3
Very

Satisfied

4

5 
8. Do you participate in religious/spiritual activities (for example going to church activities, worshipping, scripture reading, Sunday school, etc.) with family members?

YES _ N NO

\begin{tabular}{|c|c|c|c|}
\hline If YES how often? & \multicolumn{3}{|c|}{ For about how long per time? (check only one) } \\
\hline \begin{tabular}{|l|l} 
At least daily & \\
\end{tabular} & $<1$ hour & $1-2 \mathrm{hrs}$ & $2-3$ hours \\
\hline At least weekly & 3-4 hours & $4-5$ hours & 5-6hours \\
\hline At least monthly & 6-7 hours & $7-8$ hours & $8-9$ hours \\
\hline At least annually & 9-10 hours & $>10$ hours & $>1$ day \\
\hline
\end{tabular}

How satisfied are you with your participation with family members in these activities?

(please circle one)

Very

Dissatisfied

1

3

4

Very

Satisfied

5

9. Do you participate in community-based social activities (for example going to restaurants, parties, shopping, visiting friends/ neighbors, picnics, etc.) with family members?

YES _ N NO

\begin{tabular}{|c|c|c|c|}
\hline If YES how often? & \multicolumn{3}{|c|}{ For about how long per time? (check only one) } \\
\hline At least daily & $<1$ hour & $1-2 \mathrm{hrs}$ & $2-3$ hours \\
\hline At least weekly & 3-4 hours & 4-5 hours & 5-6hours \\
\hline At least monthly & 6-7 hours & 7-8 hours & 8-9 hours \\
\hline At least annually & 9-10 hours & $>10$ hours & $>1$ day \\
\hline
\end{tabular}

How satisfied are you with your participation with family members in these activities?

(please circle one)

Very

Dissatisfied

1
Very

Satisfied

\section{5}


10. Do you participate in spectator activities (for example going to movies, sporting events, concerts, plays or theatrical performances, etc.) with family members?

$$
\mathrm{YES} \text { _ } \quad \mathrm{NO}
$$

\begin{tabular}{|c|c|c|c|}
\hline If YES how often? & \multicolumn{3}{|c|}{ For about how long per time? (check only one) } \\
\hline At least daily & $<1$ hour & $1-2 \mathrm{hrs}$ & $2-3$ hours \\
\hline At least weekly & 3-4 hours & 4-5 hours & 5-6hours \\
\hline At least monthly & 6-7 hours & $7-8$ hours & 8-9 hours \\
\hline At least annually & 9-10 hours & $>10$ hours & $>1$ day \\
\hline
\end{tabular}

How satisfied are you with your participation with family members in these activities?

$$
\text { (please circle one) }
$$

Very

Dissatisfied

1
2
3
Very

Satisfied

5

11. Do you participate in community-based sporting activities (for example bowling, golf, swimming, skating, etc.) with family members?

YES _ $\quad \mathrm{NO}$

\begin{tabular}{|l|l|}
\hline \multicolumn{1}{|c|}{ If YES how often? } \\
\hline At least daily & \\
\hline At least weekly & \\
\hline At least monthly & \\
\hline At least annually & \\
\hline
\end{tabular}$\quad$\begin{tabular}{|r|r|r|r|r|r|}
\hline \multicolumn{5}{|c|}{ For about how long per time? (check only one) } \\
\hline$<1$ hour & $1-2$ hrs & & $2-3$ hours & \\
\hline $3-4$ hours & & $4-5$ hours & & $5-6$ hours & \\
\hline $6-7$ hours & & $7-8$ hours & & $8-9$ hours & \\
\hline $9-10$ hours & & $>10$ hours & & $>1$ day & \\
\hline
\end{tabular}

How satisfied are you with your participation with family members in these activities?

(please circle one)

Very

Dissatisfied

1
2

3
Very

Satisfied

4

5 
12. Do you participate in community-based special events (for example visiting museums, zoos, theme parks, fairs, etc.) with family members?

YES _ _ NO

\begin{tabular}{|l|l|}
\hline \multicolumn{2}{|c|}{ If YES how often? } \\
\hline At least daily & \\
\hline At least weekly & \\
\hline At least monthly & \\
\hline At least annually & \\
\hline
\end{tabular}

\begin{tabular}{|c|c|c|}
\hline \multicolumn{3}{|c|}{ For about how long per time? (check only one) } \\
\hline$<1$ hour & $1-2 \mathrm{hrs}$ & $2-3$ hours \\
\hline 3-4 hours & 4-5 hours & 5-6hours \\
\hline 6-7 hours & $7-8$ hours & 8-9 hours \\
\hline 9-10 hours & $>10$ hours & \\
\hline 1 day & 8 days & 15 days \\
\hline 2 days & 9 days & 16 days \\
\hline 3 days & 10 days & 17 days \\
\hline 4 days & 11 days & 18 days \\
\hline 5 days & 12 days & 19 days \\
\hline 6 days & 13 days & 20 days \\
\hline One week & Two weeks & $\begin{array}{r}3 \text { or more } \\
\text { weeks }\end{array}$ \\
\hline
\end{tabular}

How satisfied are you with your participation with family members in these activities?

(please circle one)

Very

Dissatisfied

1
2
3
Very

Satisfied

4
5 
13. Do you participate in outdoor activities (for example camping, hiking, hunting, fishing, etc.) with family members?

$$
\text { YES _ } \quad \mathrm{NO}
$$

\begin{tabular}{|l|l|r|r|r|r|r|}
\hline \multicolumn{1}{|c|}{ If YES how often? } \\
\hline At least daily & \\
\hline At least weekly & \multicolumn{5}{|c|}{ For about how long per time? (check only one) } \\
\hline At least monthly & $<1$ hour & & $1-2$ hrs & $2-3$ hours & \\
\hline At least annually & \\
\hline & $3-4$ hours & & $4-5$ hours & & $5-6$ hours & \\
\hline $6-7$ hours & & $7-8$ hours & & $8-9$ hours & \\
\hline $9-10$ hours & & $>10$ hours & & & \\
\hline 1 day & & 8 days & & 15 days & \\
\hline 2 days & & 9 days & & 16 days & \\
\hline 3 days & & 10 days & & 17 days & \\
\hline 4 days & & 11 days & & 18 days & \\
\hline 5 days & & 12 days & & 19 days & \\
\hline 6 days & & 13 days & & 20 days & \\
\hline One week & & Two weeks & & $\begin{array}{r}3 \text { or more } \\
\text { weeks }\end{array}$ \\
\hline
\end{tabular}

How satisfied are you with your participation with family members in these activities?

$$
\text { (please circle one) }
$$

Very

Dissatisfied

1
2

3
Very

Satisfied

4

5 
14. Do you participate in water-based activities (for example water skiing, jet skiing, boating, sailing, canoeing, etc.) with family members?

YES _ N N

\begin{tabular}{|c|c|c|c|}
\hline If YES how often? & \multicolumn{3}{|c|}{ For about how long per time? (check only one) } \\
\hline At least daily & $<1$ hour & $1-2 \mathrm{hrs}$ & $2-3$ hours \\
\hline At least weekly & 3-4 hours & 4-5 hours & 5-6hours \\
\hline $\begin{array}{l}\text { At least monthly } \\
\text { (during season) }\end{array}$ & 6-7 hours & $7-8$ hours & $8-9$ hours \\
\hline At least annually & 9-10 hours & $>10$ hours & \\
\hline & 1 day & 8 days & 15 days \\
\hline & 2 days & 9 days & 16 days \\
\hline & 3 days & 10 days & 17 days \\
\hline & 4 days & 11 days & 18 days \\
\hline & 5 days & 12 days & 19 days \\
\hline & 6 days & 13 days & 20 days \\
\hline & One week & Two weeks & $\begin{array}{r}3 \text { or more } \\
\text { weeks }\end{array}$ \\
\hline
\end{tabular}

How satisfied are you with your participation with family members in these activities?

(please circle one)

Very

Dissatisfied

1
Very

Satisfied

5 
15. Do you participate in outdoor adventure activities (for example rock climbing, river rafting, off-road vehicles, scuba diving, etc.) with family members?

$$
\text { YES _ } \quad \mathrm{NO}
$$

\begin{tabular}{|l|l|r|r|r|r|r|}
\hline \multicolumn{1}{|c|}{ If YES how often? } \\
\hline At least daily & \\
\hline At least weekly & \multicolumn{5}{|c|}{ For about how long per time? (check only one) } \\
\hline At least monthly & $<1$ hour & & $1-2$ hrs & $2-3$ hours & \\
\hline At least annually & 3-4 hours & $4-5$ hours & & $5-6$ hours & \\
\hline $6-7$ hours & & $7-8$ hours & & $8-9$ hours & \\
\hline $9-10$ hours & & $>10$ hours & & & \\
\hline 1 day & & 8 days & & 15 days & \\
\hline 2 days & & 9 days & & 16 days & \\
\hline 3 days & & 10 days & & 17 days & \\
\hline 4 days & & 11 days & & 18 days & \\
\hline 5 days & & 12 days & & 19 days & \\
\hline 6 days & & 13 days & & 20 days & \\
\hline One week & & Two weeks & & $\begin{array}{r}3 \text { or more } \\
\text { weeks }\end{array}$ \\
\hline
\end{tabular}

How satisfied are you with your participation with family members in these activities?

$$
\text { (please circle one) }
$$

Very

Dissatisfied

1
Very

Satisfied

4

5 
16. Do you participate in tourism activities (for example family vacations, traveling, visiting historic sites, visiting state/national parks, etc.) with family members?

YES _ $\quad \mathrm{NO}$

\begin{tabular}{|c|c|c|c|}
\hline If YES how often? & \multicolumn{3}{|c|}{ For about how long per time? (check only one) } \\
\hline At least daily & $<1$ hour & $1-2 \mathrm{hrs}$ & 2-3 hours \\
\hline At least weekly & 3-4 hours & 4-5 hours & 5-6hours \\
\hline At least monthly & 6-7 hours & $7-8$ hours & 8-9 hours \\
\hline At least annually & 9-10 hours & $>10$ hours & \\
\hline & 1 day & 8 days & 15 days \\
\hline & 2 days & 9 days & 16 days \\
\hline & 3 days & 10 days & 17 days \\
\hline & 4 days & 11 days & 18 days \\
\hline & 5 days & 12 days & 19 days \\
\hline & 6 days & 13 days & 20 days \\
\hline & One week & Two weeks & $\begin{array}{r}3 \text { or more } \\
\text { weeks }\end{array}$ \\
\hline
\end{tabular}

How satisfied are you with your participation with family members in these activities?

(please circle one)

Very

Dissatisfied

1
2
3
Very

Satisfied

4
5 
Appendix A-1c

Family Adaptability and Cohesion Evaluations Scales II 


\section{Family Adaptability and Cohesion Evaluation Scales}

Please answer the following questions in reference to your family currently. Please be as open and honest as possible. All responses are strictly confidential.

Use the following scale:
1
2
3
4
5
Almost never Once in awhile Sometimes Frequently Almost always

\section{Describe your family:}

1. Family members are supportive of each other during difficult times.

2. In our family, it is easy for everyone to express his/her opinion.

3. It is easier to discuss problems with people outside the family than with other family members.

4. Each family member has input regarding major family decisions.

5. Our family gathers together in the same room.

6. Children have a say in their discipline.

7. Our family does things together.

8. Family members discuss problems and feel good about the solutions.

9. In our family, everyone goes his/her own way.

10. We shift household responsibilities from person to person.

11. Family members know each other's close friends.

12. It is hard to know what the rules are in our family.

13. Family members consult other family members on personal decisions.

14. Family members say what they want.

15. We have difficulty thinking of things to do as a family.

16. In solving problems, the children's suggestions are followed.

17. Family members feel very close to each other.

18. Discipline is fair in our family.

19. Family members feel closer to people outside the family than to other family members.

20. Our family tries new ways of dealing with problems.

21. Family members go along with what the family decides to do.

22. In our family, everyone shares responsibilities.

23. Family members like to spend their free time with each other.

24. It is difficult to get a rule changed in our family.

25. Family members avoid each other at home.

26. When problems arise, we compromise.

27. We approve of each other's friends.

28. Family members are afraid to say what is on their minds.

29. Family members pair up rather than do things as a total family.

30. Family members share interests and hobbies with each other. 
Appendix A-1d

Family Communication Scale 


\section{Family Communication Scale}

\begin{tabular}{|c|c|c|c|c|}
\hline 1 & 2 & 3 & 4 & 5 \\
\hline $\begin{array}{c}\text { DOES NOT } \\
\text { Family at all }\end{array}$ & $\begin{array}{c}\text { SLIGHTLY } \\
\text { describes our } \\
\text { family }\end{array}$ & $\begin{array}{c}\frac{\text { SOMEWHAT }}{\text { describes our }} \\
\text { family }\end{array}$ & $\begin{array}{c}\frac{\text { GENERALLY }}{\text { describes our }} \\
\text { family }\end{array}$ & $\begin{array}{c}\frac{\text { VERY WELL }}{\text { describes our }} \\
\text { family }\end{array}$ \\
\hline & & & & \\
\hline
\end{tabular}

1. Family members are satisfied with how they communicate with each other.

2. Family members are very good listeners.

3. Family members express affection to each other.

4. Family members are able to ask each other for what they want.

5. Family members can calmly discuss problems with each other.

6. Family members discuss their ideas and beliefs with each other.

7. When family members ask questions of each other, they get honest answers.

8. Family members try to understand each other's feelings

9. When angry, family members seldom say negative things about each other. 10. Family members express their true feelings to each other. 
Appendix A-1e

Demographic Questions 


\section{The following section asks some general questions about you and your family.}

Please complete the following on your current family. In addition, please indicate your relationship to each child in your family.

\begin{tabular}{|c|c|c|c|c|c|}
\hline & Age & Sex & $\begin{array}{c}\text { Ethnic } \\
\text { Background }\end{array}$ & $\begin{array}{c}\text { Lives in } \\
\text { your } \\
\text { home }\end{array}$ & $\begin{array}{c}\text { Your } \\
\text { relationship } \\
\text { to Child }\end{array}$ \\
\hline & $\begin{array}{l}\text { In } \\
\text { Years }\end{array}$ & $\mathbf{M}$ or $\mathbf{F}$ & $\begin{array}{l}\mathbf{A}=\text { Asian } \\
\mathbf{P}=\text { Pacific Islander } \\
\mathbf{B}=\text { Black not Hispanic } \\
\mathbf{H}=\text { Hispanic } \\
\mathbf{N}=\text { Native American } \\
\mathbf{W}=\text { White, not Hispanic }\end{array}$ & $\begin{array}{l}\text { Yes or } \\
\text { No }\end{array}$ & $\begin{aligned} \mathbf{B}=\text { Birth Parent } \\
\mathbf{A}=\text { Adoptive Parent } \\
\mathbf{S}=\text { Step-Parent } \\
\mathbf{F}=\text { Foster Parent } \\
\mathbf{P}=\text { Partner of child's } \\
\quad \text { birth, adoptive, or } \\
\quad \text { step-parent } \\
\mathbf{L}=\text { Legal Guardian }\end{aligned}$ \\
\hline \multicolumn{6}{|l|}{$\mathrm{YOU}$} \\
\hline \multicolumn{6}{|l|}{ Child } \\
\hline \multicolumn{6}{|l|}{ Child } \\
\hline \multicolumn{6}{|l|}{ Child } \\
\hline \multicolumn{6}{|l|}{ Child } \\
\hline \multicolumn{6}{|l|}{ Child } \\
\hline Child & & & & & \\
\hline
\end{tabular}

Marital status - Check all that apply to you currently:

Single-never married

Married -- If yes, how many years to current spouse?

(in years)

Unmarried-- Living with partner

Separated -- If yes, how long have you been separated?

Divorced -- If yes, how long have you been divorced?

(in years)

Widowed -- If yes, how long have you been widowed?

(in years)

(in years)

Other-please specify

(in years)

Have you ever been divorced? Yes___ No ___ If so, how many times?

Please indicate the estimated annual income for your family.
Less than $\$ 10,000$
$40,000-49,999$
$50,000-59,999$
$80,000-99,999$
$10,000-19,999$
$60,000-69,999$
$100,000-124,999$
$20,000-29,999$
$70,000-79,999$
$125,000-150,000$
$30,000-39,999$
$-70,000-79,999$
Over $\$ 150,000$

State currently living in

Population of your place of residency: Please circle one
Urban/Suburban $(>50,000)$
or Rural $(<\mathbf{5 0 , 0 0 0 )}$ 